\title{
Evaluation and optimization of organic Rankine cycle (ORC) with algorithms NSGA-II, MOPSO, and MOEA for eight coolant fluids
}

\author{
E. Ghasemian ${ }^{1} \cdot$ M. A. Ehyaei ${ }^{1}$
}

Received: 30 April 2017/Accepted: 12 October 2017/Published online: 26 October 2017

(C) The Author(s) 2017. This article is an open access publication

\begin{abstract}
In this study, a simple organic cycle for eight subcritical coolant fluids has been studied thermodynamically and economically. For all the coolants, the present cycle was optimized for the best thermal and exergy efficiencies and the best cost of energy production. In a multipurpose procedure, using the three methods NSGA-II, MOPSO, and MOEA/D, design variables in the optimization are the inlet turbine pressure and temperature, the pinch temperature difference, the proximity temperature difference in regenerator exchanger, and condenser temperature difference. The optimization results show that, in all three methods, the impact of the parameters' inlet turbine temperature and pressure on the three objective functions is much more than other design parameters. Coolant with positive temperature gradients shows a better performance but lower produced power. In optimization methods, among all the coolants, the MOPSO method showed higher thermal and energy efficiency, and the MOEA/D showed lower production power costs. In terms of the rate of convergence, also both the MOPSO and NSGA-II methods showed better performance. The fluid $\mathrm{R}_{11}$ with the $25.7 \%$ thermal efficiency, $57.3 \%$ exergy efficiency, and 0.054 USD cost per kWh showed the best performance among all of the coolants.
\end{abstract}

Keywords Optimization - Organic Rankine cycle · Coolant fluid · Exergy

M. A. Ehyae

aliehyaei@yahoo.com

1 Department of Mechanical Engineering, Pardis Branch, Islamic Azad University, Pardis New City, Iran

\section{Abbreviations}

$\dot{Q} \quad$ Heat transfer rate $(\mathrm{kW})$

$\dot{W} \quad$ Power $(\mathrm{kW})$

$\dot{m} \quad$ Mass flow rate $(\mathrm{kg} / \mathrm{s})$

$h_{\text {out }} \quad$ Outlet enthalpy $(\mathrm{kJ} / \mathrm{kg})$

$h_{\text {in }} \quad$ Inlet enthalpy $(\mathrm{kJ} / \mathrm{kg})$

$\dot{\mathrm{Ex}}_{i} \quad$ Exergy rate of each component $(\mathrm{kW})$

$s \quad$ Entropy of each component $(\mathrm{kJ} / \mathrm{kg} \mathrm{K})$

$T_{0} \quad$ Ambient temperature (K)

$\dot{I} \quad$ Irreversibility $(\mathrm{kW})$

$\dot{S}_{\text {gen }} \quad$ Entropy $(\mathrm{kW} / \mathrm{K})$

$\dot{\mathrm{Ex}}$ out $\quad$ Outlet exergy flow $(\mathrm{kW})$

Ė $x_{\text {in }} \quad$ Inlet exergy flow $(\mathrm{kW})$

$q_{j} \quad$ Transferred heat per mass $(\mathrm{kJ} / \mathrm{kg})$

$T_{j} \quad$ Temperature of each component (K)

$\Delta T_{\mathrm{pp}} \quad$ Pinch temperature difference at regenerator $(K)$

$T_{\mathrm{H} 3} \quad$ Evaporator outlet temperature at the heated area of regenerator $(K)$

$T_{7 \mathrm{~b}} \quad$ Evaporator inlet temperature at the heated area of regenerator $(K)$

$\Delta T_{\text {ap }} \quad$ Proximity temperature difference at the regenerator $(K)$

$T_{7 \mathrm{a}} \quad$ Preheat outlet temperature at the cooled area of regenerator $(K)$

$\dot{m}_{\mathrm{WF}} \quad$ Organic cycle fluid mass flow rate discharge $(\mathrm{kg} / \mathrm{s})$

$\dot{m}_{H} \quad$ Heat transferring hot fluid mass flow rate discharge $(\mathrm{kg} / \mathrm{s})$

$I_{\text {HRVG }}$ Total wasted exergy at heat regenerator transducer $(\mathrm{kW})$

$\eta_{\mathrm{ST}} \quad$ Turbine isentropic efficiency

$\eta_{\text {mech }} \quad$ Mechanic efficiency of the shaft connected to the generator

$\dot{W}_{\text {ST }} \quad$ Turbine power production $(\mathrm{kW})$ 


\begin{tabular}{|c|c|}
\hline$\dot{W}_{\text {gen }}$ & Generator power production $(\mathrm{kW})$ \\
\hline$s_{1}$ & Inlet turbine entropy $(\mathrm{kJ} / \mathrm{kg} \mathrm{K})$ \\
\hline$P_{2}$ & Outlet turbine pressure (MPa) \\
\hline$I_{\mathrm{ST}}$ & Wasted exergy in steam turbine $(\mathrm{kW})$ \\
\hline$v_{1}, v_{2}$ & $\begin{array}{l}\text { Specific volume of the turbine inlet and outlet } \\
\text { fluid }\left(\mathrm{m}^{3} / \mathrm{kg}\right)\end{array}$ \\
\hline VER & The expansion of the fluid in steam turbines \\
\hline$\dot{m}_{\text {Coolant }}$ & $\begin{array}{l}\text { Flow discharge of cooling water in the } \\
\text { condenser }\left(\frac{\mathrm{kg}}{\mathrm{s}}\right)\end{array}$ \\
\hline$\Delta T_{\text {Cond }}$ & $\begin{array}{l}\text { Fluid temperature difference at the outlet of the } \\
\text { condenser }(\mathrm{K})\end{array}$ \\
\hline$I_{\text {Cound }}$ & Wasted exergy in condenser $(\mathrm{kW})$ \\
\hline$\eta_{\mathrm{P}}$ & Pump isentropic efficiency \\
\hline$h_{4}, h_{5}$ & Enthalpy of the pump inlet and outlet $(\mathrm{kJ} / \mathrm{kg})$ \\
\hline$\dot{W}_{\mathrm{P}}$ & Consumption power of pump $(\mathrm{kW})$ \\
\hline$\dot{W}_{\text {net }}$ & Net power production $(\mathrm{kW})$ \\
\hline BWR & $\begin{array}{l}\text { Ratio of the work needed by the pump to the } \\
\text { work made by steam turbine }\end{array}$ \\
\hline$\eta_{\mathrm{th}}$ & Organic Rankine cycle thermal efficiency \\
\hline$C_{\text {Equ }}$ & Steam turbine purchase cost (US\$) \\
\hline$C_{\mathrm{Gen}}$ & Pump purchase cost (US\$) \\
\hline$C_{\mathrm{HRVG}}$ & Heat regenerator purchase cost (US\$) \\
\hline$C_{\text {cound }}$ & Condenser purchase costs (US\$) \\
\hline$C_{\mathrm{ST}}$ & Total cost (US\$) \\
\hline$C_{\mathrm{P}}$ & Power generator cost (US\$) \\
\hline$C_{\text {miscella }}$ & Miscellaneous cost (US\$) \\
\hline$C_{\mathrm{T}}$ & Total annual costs of investment (US\$) \\
\hline $\mathrm{CRF}$ & Irreversibility factor \\
\hline$C_{\mathrm{O \& M}}$ & $\begin{array}{l}\text { Annual costs of equipment maintenance(US\$/ } \\
\text { year) }\end{array}$ \\
\hline$\left(\dot{C}_{\text {anu }}\right)$ & $\begin{array}{l}\text { Annual investment costs of equipment, } \\
\text { maintenance, and fuel }\end{array}$ \\
\hline$\beta$ & Percentage of maintenance costs \\
\hline LHV & $\begin{array}{l}\text { Low thermal value of the selected fuel per }(\mathrm{kJ} / \\
\mathrm{kg})\end{array}$ \\
\hline$\dot{c}_{\text {fuel }}$ & $\begin{array}{l}\text { Costs of each kilogram of fuel consumed (US\$/ } \\
\mathrm{kW} \text { ) }\end{array}$ \\
\hline $\mathrm{H}$ & $\begin{array}{l}\text { Annual working hours of the system per (hour/ } \\
\text { year) }\end{array}$ \\
\hline$C_{\mathrm{kWh}}$ & $\begin{array}{l}\text { Costs of production each kilowatt of energy per } \\
\text { hour }\end{array}$ \\
\hline $\mathrm{OF}$ & Desired objective function amount \\
\hline
\end{tabular}

\section{Introduction}

The increasing consumption of fossil fuels causes greenhouse gas emissions, global warming, and environmental degradation. Shortage of fossil fuels and the gradual rise in their cost and environmental pollution have caused a major consideration to use of energy with low or moderate temperatures. Meanwhile, the ORC (organic Rankine cycle) technology may have an important role. This cycle has a function similar to steam Rankine cycle with different that it uses organic working fluids instead of water. Due to the low critical temperature of organic fluid as compared to water, the organic Rankine cycle, unlike the steam Rankine cycle, will be able to use the low-temperature heat sources, including industrial waste temperatures or renewable energy sources such as solar, geothermal, and biomass $[12,19]$.

In the last 20 years, the use of organic Rankine cycle instead of a simple Rankine cycle has been considered The operating ORC power plants around the world, with capacities ranging from $200 \mathrm{~kW}$ to $130 \mathrm{MW}$, demonstrate special attention to this technology. This cycle uses heat sources with low temperatures $\left(100-500{ }^{\circ} \mathrm{C}\right)$. The ORC cycle works based on the simple Rankine cycle; however, to work with organic fluids, some changes must be applied. Organic working fluid in the ORC could be selected from the hydrocarbons; however, inorganic materials such as silicon and refrigeration fluids can also be used. ORC technology is significantly used in waste heat recycling of waste heat from gas turbines and it has significant advantages compared to classical heat regenerator system using a conventional Rankine cycle [12, 19]. A great deal of research has been done in the field of organic Rankine cycle. Yamamato et al. [23] examined an organic Rankine cycle using HCFC-123 as a working fluid and concluded that this system has a better performance compared to using water as the working fluid [23]. Liu et al. [10] studied the effects of different working fluid on thermal and heat regenerator efficiencies. It showed that the wet fluid is inappropriate for ORC systems [10]. Wei et al. [22] studied the analysis and optimization of organic Rankine cycle using (1,1,1,3,3 penta-fluoro-propane) HFC-FA245 as the working fluid. The results showed that the use of the output heat is a good solution to improve the system efficiency and net output power. The condenser outlet cooling degree should be small $(0.5-0.6 \mathrm{~K})$. When the ambient temperature is high, system output power and efficiency was reduced about $30 \%$ from the nominal value. [22]. Saleh et al. [16] examined 31 fluids for the organic Rankine cycle operations in extremely low temperature and pressure, based on backbone relationship. Fluids include: alkanes, fluorinated alkanes, fluorinated ethers, and esters. Cycles operated between 30 and $100{ }^{\circ} \mathrm{C}$ in geothermal power plants under pressures limited to 20 Bar; however, in some cases, the supercritical pressures are considered. The thermal efficiency of operating fluids $\mathrm{R}_{125}$ and $\mathrm{C}_{5} \mathrm{~F}_{12}$, is 2.3 and $10.5 \%$, respectively [16]. Tchanche et al. [18] analyzed the thermodynamic characteristics and functions of 20 fluids in the solar ORCs, in low temperature, and suggested R134a as the best fluid [18]. 
Roy et al. [15] studied functional analysis and parameter optimization of a heat regenerator system, using fluids R-12, R-123, and R-134A, based on ORC technology. Three different fluids were selected for this study and the productivity and Carnot efficiency were compared. The considered parameters were the output work and system efficiency. The results showed that R-123 has the maximum output power and efficiency. Carnot efficiency for this fluid, in modified pressure and under the similar conditions, is close to real state. Therefore, choosing the organic Rankine cycle with the fluid R-123 seems to be an ideal system for using the low-temperature heat sources in power generation Roy et al. [15].

Rayegan and Tao [14] have developed an approach to choose the working fluid for the solar organic Rankine cycle. ORC fluid selection is critical point of performance; therefore, some of available research will focus on fluid selection. The Ref-prop 8 database with 117 fluids was chosen for this study. An approach for comparison of ORC working fluids was proposed based on molecular components, enthalpy versus temperature, thermal efficiency, net power production, and exergy efficiency of ORC. Fluids with best cycle performance were identified in two different categories based on two different temperature levels: coolant and non-coolant. According to the solar collectors, 11 fluids were proposed to be used in solar OCRs which used low- or medium-heat solar collectors. The results showed that for the fluid selection, theoretical constraints to reduce irreversibility and exergy efficiency by improving the efficiency of the collector are 35 and 5\%, respectively, when the collector's efficiency is increased from 70 to $100 \%$. Reconstruction impact on exergy efficiency is dependent on the fluid while improving the efficiency of the collector on exergy efficiency is independent of the type of fluid [14].

Wang et al. [20] presented the working fluid selection and parametric optimization. They used a multi-objective optimization procedure to evaluate an ORC cycle. Target functions were output power per unit input heat and thermal efficiency. Independent parameters were evaporation and condensation pressure, type of working fluid, and the speed of water cooling in the pipes. By comparing the optimization results for 13 working fluids, they showed that the economic characteristics of the system are quickly decreased with the reduction in source's temperature. They concluded that when the heat source temperature is below $100{ }^{\circ} \mathrm{C}$, the ORC technology is non-economic [20].

Ahmadi and Rosen [1] examined a triple comprehensive generation model consisting of a triple system for cooling, heating, and power generation which includes a cycle gas turbines, organic Rankine cycle, a single-effect absorption cooler, and a conventional water heater. The results are as follows: greater exergy efficiency and less carbon dioxide emission from the tri-generation system compared to combined heating and power systems or gas turbine cycles. The greatest exergy destruction was happened in combustion chamber due to chemical reactions and high-temperature difference between the working fluid and medium. Parametric studies showed that the compressor pressure ratio, gas turbine inlet temperature, and isentropic efficiency of gas turbines greatly affected on the exergy efficiency and environmental impact of the tri-generation systems. In addition, with the increase in turbine inlet temperature, the environmental impact costs are primarily reduced by the decrease in combustion chamber volume flow rate [1].

Pierobon et al. [11] found the MW-size optimal organic Rankine cycles using the multi-objective optimization with genetic algorithms. They had three objective functions: the thermal efficiency, the total volume of the system, and the net present value. The variables of the working fluid optimization were the turbine inlet temperature, pressure, and the temperature of flow rate at the compact heat exchangers. They used this approach to retrieve the waste heat from gas turbines SGI-500 installed on draugen oil and gas platform in the North Sea. Optimization results showed that the thermal efficiency and net present value for cyclopentane are higher than acetone [11]. Wang et al. [21] used a genetic algorithm as the optimization method for a comparative study of ORC and working fluid R-134A, for low-grade waste heat regenerator. Exergy efficiency and total investment costs were considered as the objective function to optimize the waste heat under certain conditions. The obtained Pareto efficiency indicated that the increase in exergy efficiency can increase the total investment costs for the ORC system [21].

Quoilin et al. [12] explained the current state of ORC technology with emphasis on heating values and the properties of each fluid. The working fluids and expansion equipment's are the two characteristics of ORC technology. This research has investigated numerous studies on working fluids in the literature and also noted the limitations. In their research, the review on different applications of ORC has been provided. A proposed market review includes forms of the costs for several ORC business units and producers. A precise analysis of the technical challenges related to this technology has been reported, such as the working fluid and the expansion device issues. Technological constraints and optimization methods are widely described and discussed [12].

Ataei et al. [3] conducted thermodynamic assessments based on the first and second laws of thermodynamics to simulate the different organic fluids and different ORC states in different ambient temperatures by the use of engineering equation solver (EES) and assess the environmental functions using the sustainability method. 
Energy analysis showed that ORC renovated with IHE (intermediate heat exchanger) had the best thermodynamics performance. In this study, it was revealed that $\mathrm{N}$-hexane, which has the highest boiling point and critical temperature, is the most efficient working fluid for the cycle. The results showed that a decrease in ambient temperature caused an increase in first and second law efficiencies and made the system more stable [3].

Darvish et al. [7] simulated the thermodynamic performance of a regenerative organic Rankine cycle that uses low-temperature heat sources. They made use of thermodynamic models to evaluate the thermodynamic parameters such as power output and energy efficiency of ORC. In addition, in this study, the cost of electricity was estimated by the exergy-economic analysis. The working fluid was considered as a part of evaluation to identify the highest power output and energy efficiency in the specific system conditions. [7].

Ashouri et al. [2] studied an ORC in terms of thermodynamics and economic for power generation with a small-scale up to $100 \mathrm{~kW}$. This parametric study indicated the impact of key parameters such as temperature and turbine inlet pressure on the parameters of the system such as network, thermal efficiency, oil and total heat transfer coefficient, the heat transfer area of the thermal exchangers of the shell and tube, as well as the system costs. The results showed that the dependency of system efficiency and its cost on operating pressure of heat exchangers. They proved that the existence of regenerator is relatively effective on the increase in cycle efficiency, and in some cases, it reduces the overall costs due to reduction in condenser load. The comparison between different working fluids such as benzene, butane, pentane, iso-pentane, $\mathrm{R}_{123}$, and $\mathrm{R}_{245} \mathrm{FA}$ was conducted to detect a wide range of operational pressures and temperatures. The results showed that benzene has the best thermodynamic performance among the other fluids, and after it, isopentane, $\mathrm{R}_{123}, \mathrm{R}_{245} \mathrm{FA}$, and butane showed the best performance. Benzene also has the highest cost of all the other fluids and after it come pentane, isopentane, butane, $R_{123}$, and $\mathrm{R}_{245} \mathrm{FA}$ [2].

In this paper, a simple organic cycle for eight subcritical coolants was studied thermodynamically and economically. For all the coolants, the current cycle was optimized for the best exergy and thermal efficiency as well as the best production cost in a multi-objective functions, using the three methods NSGA-II, MOPSO, and MOEA/D. Regarding the previous studies, the innovations of the current study are:

- using new equations to calculate the cost of the equipment installed in an organic Rankine cycle;
- tri-objective optimization (cost, exergy efficiency, and thermal efficiency) by changing the five design variables;

- using three optimization methods NSGA-II, MOPSO, and MOEA/D to compare the results of these three methods.

\section{Analysis of exergy and energy}

In general, the organic Rankine cycle includes heat regenerator, turbines, condenser, and pump. This cycle is divided into hypercritical and subcritical categories according to turbine inlet pressure. The current research has been done on subcritical cycle.

Temperature-entropy diagram of the subcritical cycle in the state in which the turbine inlet fluid is superheated (superheat state), as shown in Fig. 1. In this case, if the turbine inlet temperature (point 2) is above the inlet temperature heat regenerator (point 6), a middle regenerator can be used to reduce the turbine outlet fluid temperature before entering the condenser and increase the pump outlet fluid temperature before entering the regenerator. First law of thermodynamics regardless of changes in steady-state kinetic and potential energy for each component is expressed as follows:

$\dot{Q}-\dot{W}=\dot{m}\left(h_{\text {out }}-h_{\text {in }}\right)$,

in which $\dot{Q}, \dot{W}, \dot{m}, h_{\text {out }}$, and $h_{\text {in }}$ are the heat transfer $(\mathrm{kW})$, output power $(\mathrm{kW})$, the mass flow rate through each component $\left(\frac{\mathrm{kg}}{\mathrm{s}}\right)$, and enthalpy of input and output $\left(\frac{\mathrm{kJ}}{\mathrm{kg}}\right)$, respectively.

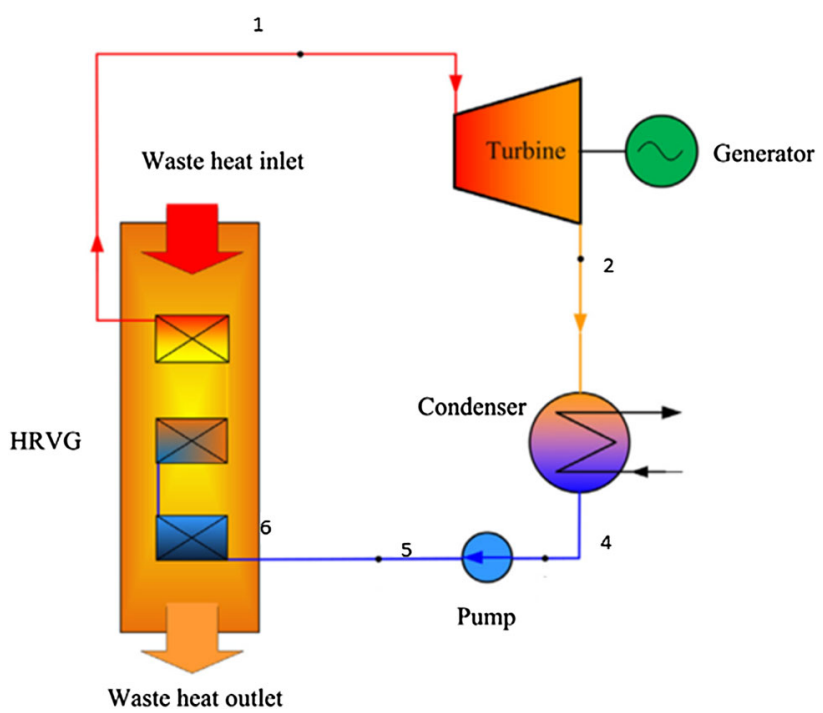

Fig. 1 Schematic of organic Rankine cycle [19] 
By considering ambient temperature and pressure as the basis, the exergy rate of any part of is calculated by the following equation [4]:

$\dot{\mathrm{Ex}_{i}}=\dot{m}\left(\left(h_{i}-h_{0}\right)-T_{0}\left(s_{i}-s_{0}\right)\right)$,

in which $\dot{E x}_{i}$ is the exergy rate of each part $(\mathrm{kW}), S$ is the entropy of each part per $\left(\frac{\mathrm{kJ}}{\mathrm{kg} \mathrm{K}}\right)$, and $T_{0}$ is the ambient temperature per $(\mathrm{K})$.

Subscript 0 the basic state which equals the environmental conditions at $15^{\circ} \mathrm{C}$ and pressure of $1 \mathrm{~atm}$.

Exergy balance for each open thermodynamic system can be shown as follows [4]:

$\dot{I}=T_{0} \dot{S}_{\text {gen }}=\dot{\mathrm{E}} \mathrm{x}_{\mathrm{in}}-\dot{\mathrm{E}} \mathrm{x}_{\mathrm{out}}$,

in which $\dot{I}, \dot{S}_{\text {gen }}, \dot{E} x_{\text {out }}$, and $\dot{E x}_{\text {in }}$ are irreversibility $(\mathrm{kW})$, entropy generation $\left(\frac{\mathrm{kW}}{\mathrm{K}}\right)$, and exergy of input and output flow $(\mathrm{kW})$.

The heat regenerator in the organic cycle is divided into three parts as preheater, evaporators, and super-heater. Organic fluid, at the two locations of the preheater and super-heater, is single phase and it are two phases at evaporator. Usually, the heat exchanger in an organic cycle is in the form of a single cross flow.

Heat exchanger performance depends on different constraints. One of the most important parameters affecting the operation of the exchanger is the temperature difference between organic fluid in the evaporator and outlet temperature. This temperature difference is known as the Pinch temperature difference. In fact, in terms of engineering, the designer likes this temperature difference to tend toward zero. However, the design costs, by reducing this temperature difference due to significant increase in the heat transfer area of the evaporator, are significantly increased. That is why finding the optimal temperature difference for the heat exchanger design is essential [21]:

$\Delta T_{\mathrm{pp}}=T_{\mathrm{H} 3}-T_{7 \mathrm{~b}}$,

in which $\Delta T_{\mathrm{pp}}$ is the pinch temperature difference in the heat regenerator exchanger and $T_{\mathrm{H} 3}$ is the evaporator outlet temperature at heated area of regenerator and $T_{7 \mathrm{~b}}$ is the evaporator inlet temperature at the cool area of the regenerator $(\mathrm{K})$.

Organic fluid outlet of the preheater should always be in the sub-cooled region and in single phase. If the vapor is created at outlet of the preheater, the equipment life and performance will be affected. That is why the temperature difference between the evaporator temperature and the outlet of the preheater is defined. This temperature difference is called proximity temperature difference [21]:

$\Delta T_{\text {ap }}=T_{7 \mathrm{~b}}-T_{7 \mathrm{a}}$, in which $\Delta T_{\text {ap }}$ is proximity temperature difference in regenerator $(\mathrm{K}), T_{7 \mathrm{~b}}$ is the evaporator inlet temperature at the cooled area of regenerator $(\mathrm{K})$, and $T_{7 \mathrm{a}}$ is the preheater outlet temperature at the cooled area of the regenerator $(\mathrm{K})$.

Steam temperature and pressure of the organic fluid has a very clear impact on the performance of the system. Close to the critical pressure, a tiny change in temperature leads to huge changes in pressure and system instability. That is why the pressure or outlet steam temperature of the heat exchanger must be always lower than critical temperature and pressure of organic fluid. Various methods and constraints have been suggested. For example, Ref. [14] suggests that vapor pressure is always less than the critical pressure. Or Ref. [18] states that steam temperature should be considered around $10-15^{\circ} \mathrm{C}$ lower than the critical temperature. First law of thermodynamics equations for different parts of the heat exchanger and also the whole exchanger is calculated as follows:

$\dot{Q}_{\mathrm{PH}}=\dot{m}_{\mathrm{WF}}\left(h_{7 \mathrm{a}}-h_{6}\right)=\dot{m}_{\mathrm{H}}\left(h_{\mathrm{H} 3}-h_{\mathrm{H} 4}\right)$

$\dot{Q}_{\mathrm{Eva}}=\dot{m}_{\mathrm{WF}}\left(h_{8}-h_{7 \mathrm{~b}}\right)=\dot{m}_{\mathrm{H}}\left(h_{\mathrm{H} 2}-h_{\mathrm{H} 3}\right)$

$\dot{Q}_{\mathrm{Sh}}=\dot{m}_{\mathrm{WF}}\left(h_{1}-h_{8}\right)=\dot{m}_{\mathrm{H}}\left(h_{\mathrm{H} 1}-h_{\mathrm{H} 2}\right)$

$\dot{Q}_{\mathrm{HRVG}}=\dot{m}_{\mathrm{WF}}\left(h_{1}-h_{6}\right)=\dot{m}_{\mathrm{H}}\left(h_{\mathrm{H} 1}-h_{\mathrm{H} 4}\right)$.

In the above equations, $\dot{m}_{\mathrm{WF}}$ and $\dot{m}_{\mathrm{H}}$ are the cycle organic fluid's mass flow rate and heat transfer fluid's mass flow rate in the regenerator $\left(\frac{\mathrm{kg}}{\mathrm{s}}\right)$, and $\dot{Q}$ is the rate of transferred heat at any location $(\mathrm{kW})$.

The total amount of exergy destruction in regenerator heat exchanger is calculated from the following equation:

$\dot{I}_{\mathrm{HRVG}}=\dot{\mathrm{E}} \mathrm{x}_{6}-\dot{\mathrm{E}} \mathrm{x}_{1}+\dot{\mathrm{E}} \mathrm{x}_{\mathrm{H} 1}-\dot{\mathrm{Ex}} \mathrm{H}_{\mathrm{H} 4}$

$\dot{E x}$ is any exergy rate which is calculated from Eq. (2).

The organic fluid's output vapor is expanded through a turbine. The turbine's performance is calculated as follows:

$\eta_{\mathrm{ST}}=\frac{h_{1}-h_{2}}{h_{1}-h_{2, \mathrm{~s}}}$

$\dot{W}_{\mathrm{ST}}=\dot{m}_{\mathrm{WF}}\left(h_{1}-h_{2}\right)$

$\dot{W}_{\text {gen }}=\eta_{\text {mech }} \cdot \dot{W}_{\mathrm{ST}}$,

in which $\eta_{\mathrm{ST}}$ is turbine isentropic efficiency and $\eta_{\text {mech }}$ is the mechanical efficiency of the shaft connected to generator, $h_{1}$ and $h_{2}$ are the input and output enthalpies of turbine $\left(\frac{\mathrm{kJ}}{\mathrm{kg}}\right), \dot{m}_{\mathrm{WF}}$ is the inlet mass flow rate to the turbine $\left(\frac{\mathrm{kg}}{\mathrm{S}}\right)$, and $\dot{W}_{\mathrm{ST}}$ and $\dot{W}_{\text {gen }}$ are the turbine and generator produced power $(\mathrm{kW})$.

In the above equations, $h_{6, \mathrm{~s}}$ is the outlet isentropic enthalpy from the turbine which is calculated as follows:

$h_{2 \mathrm{~s}}=\operatorname{Enthalpy}\left(s=s_{1}, P=P_{2}\right)$. 
In the above equation, $s_{1}$ is the inlet entropy to the turbine $\left(\frac{\mathrm{kJ}}{\mathrm{kg} \mathrm{K}}\right)$ and $P_{2}$ is the outlet pressure from the turbine $(\mathrm{kPa})$.

The exergy destruction by the steam turbine is calculated by the following equation:

$\dot{I}_{\mathrm{ST}}=\dot{\mathrm{E}} \mathrm{x}_{1}-\dot{\mathrm{E}} \mathrm{x}_{2}$

in which $\dot{E x}_{1}$ and $\dot{E} x_{2}$ are the amounts of input and output exergy of the steam turbine. The exergy amount in any points can be calculated from Eq. (2).

On the turbine outlet, the steam quality is a highly significant, since the reduction of this quality can lead to the decrease in the operating life of the turbine blades. Therefore, in the wet organic fluids, the vapor quality should always be higher than a specific level. That is why in these fluids, the output vapors from the heat exchanger must always be in superheat region. However, in the dry organic fluids, we do not have such a problem, and therefore, it is not necessary for the turbine inlet vapor to be in superheat area [19]. In addition, since the outlet discharge volume specifies the size and cost of the turbine, this volume ratio increase must be taken into consideration in the design calculations. The higher the expansion causes the steam turbine size will be increased, which leads to the increase in equipment costs [19]:

$\dot{V}_{1}=\dot{m}_{\mathrm{WF}} \cdot v_{1}$

$\dot{V}_{2}=\dot{m}_{\mathrm{WF}} \cdot v_{2}$

$\mathrm{VER}=\frac{\dot{V}_{2}}{\dot{V}_{1}}$.

In the above equations, $v_{1}$ and $v_{2}$ are the specific volume of the input and output fluid of turbine $\left(\frac{\mathrm{m}^{3}}{\mathrm{~kg}}\right)$, and VER is the rate of fluid expansion ratio of the steam turbine.

The condenser is another heat exchanger that changes the cooling fluid flow or regenerative steam turbine output into the saturated fluid. Usually, in the condenser, the temperature difference between cooling fluid and the condenser outlet organic fluid is taken as the main parameter affecting the organic cycle designed. It should be noted that temperature is calculated according to the condenser pressure. The energy equation and the amount of heat loss in the condenser using the conservation of energy are calculated as follows:

$\dot{Q}_{\mathrm{Cond}}=\dot{m}_{\mathrm{WF}}\left(h_{3}-h_{4}\right)=\dot{m}_{\text {Coolant }}\left(h_{\mathrm{C} 3}-h_{\mathrm{C} 1}\right)$

$T_{4}=\Delta T_{\text {Cond }}+T_{\mathrm{C} 1}$

$P_{4}=\operatorname{Pressusre}\left(T=T_{4}, X=0\right)$.

In the above equations, $\dot{m}_{\text {Coolant }}$ is the cooling water discharge in the condenser $\left(\frac{\mathrm{kg}}{\mathrm{S}}\right) . \Delta T_{\text {Cond }}$ is the condenser outlet fluid temperature difference $\left({ }^{\circ} \mathrm{C}\right)$, and $T_{4}$ is the cooling water temperature inlet to the condenser $\left({ }^{\circ} \mathrm{C}\right), T_{\mathrm{C} 1}$ which is entered into the modelling as the input $\left({ }^{\circ} \mathrm{C}\right)$. The condenser outlet pressure $P_{4}$ is calculated by the assumption of saturation fluid (MPa). The exergy destruction in the condenser is calculated by the following equation:

$\dot{I}_{\mathrm{Cond}}=\dot{\mathrm{E}} \mathrm{x}_{3}-\dot{\mathrm{E}} \mathrm{x}_{4}+\dot{\mathrm{E}} \mathrm{x}_{\mathrm{C} 1}-\dot{\mathrm{E}} \mathrm{x}_{\mathrm{C} 3}$.

In the above equation, Ex are the exergy amount on the inlet of the heated area of condenser $\dot{E x}_{3}$, the heated area outlet $\dot{E} x_{4}$, inlet of cooled area $\dot{E} x_{\mathrm{C} 1}$, and outlet of cooled area $\dot{E} x_{\mathrm{C} 3}$, which can be calculated from Eq. (2). The pump is responsible for increasing the pressure of the fluid and delivering it to the evaporator design pressure. Just like the turbine's performance, the pump's performance is also specified by the isentropic efficiency. In addition, the pump work is calculated. One of the most important parameters in the design of the organic cycle is the ratio of the pump efficiency to the turbine's efficiency. By reduction of this ratio, system efficiency will be promoted [1]. In designing the organic cycles, especially in designing the condensers, it should be ensured that the condenser pressure always be lower than evaporator:

$\eta_{\mathrm{p}}=\frac{h_{5 \mathrm{~s}}-h_{4}}{h_{5}-h_{4}}$

$\dot{W}_{\mathrm{p}}=\dot{m}_{\mathrm{wf}}\left(h_{5}-h_{4}\right)$

$\dot{W}_{\text {net }}=\dot{W}_{\mathrm{st}}-\dot{W}_{\mathrm{p}}$

$\mathrm{BWR}=\frac{\dot{W}_{\mathrm{p}}}{\dot{W}_{\mathrm{st}}}$

In the above equations, $\eta_{\mathrm{p}}$ is the isentropic efficiency of the pump, $h_{4}$ and $h_{5}$ are the enthalpy of the input and output of fluid of the pump $\left(\frac{\mathrm{kJ}}{\mathrm{kg}}\right), \dot{W}_{\mathrm{p}}$ is the input power of the pump $(\mathrm{kW})$, and $\dot{W}_{\text {net }}$ is a net power produced by the system $(\mathrm{kW})$. The lower this parameter, the better the performance of the system will be. $h_{5 \mathrm{~s}}$ is also the pump outlet isentropic enthalpy which is calculated as follows:

$h_{5 \mathrm{~s}}=\operatorname{Enthalpy}\left(P=P_{5}, s=s_{4}\right)$.

The rate of irreversibility in the pump is calculated by the following equation:

$\dot{I}_{\mathrm{p}}=\dot{\mathrm{Ex}} \mathrm{x}_{4}-\dot{\mathrm{Ex}} \mathrm{x}_{5}$

in which $\dot{E x}_{4}$ and $\dot{E x}_{5}$ are the rates exergy on the pump inlet and outlet which is calculated by Eq. 2. Organic Rankine cycle thermal efficiency is calculated as follows. The thermal efficiency is defined as the system useful power divided by the heat absorbed from the inlet heated fluid by the system's thermal regenerator: 
$\eta_{\mathrm{th}}=\frac{\dot{W}_{\mathrm{net}}}{\dot{Q}_{\mathrm{HRVG}}}$

The total amount of the rate of irreversibility in the system is calculated as follows through the sum of all the wasted exergy from different components and also the exergy efficiency of the cycle is calculated by Eq. (31). In fact, the exergy efficiency is in the form of the working rate divided by the sum of the working rate and irreversibility [6]:

$\dot{I}_{\mathrm{tot}}=\dot{I}_{\mathrm{HRVG}}+\dot{I}_{\mathrm{p}}+\dot{I}_{\mathrm{st}}+\dot{I}_{\mathrm{Cond}}$

$\eta_{\text {Exe }}=\frac{\text { Exergy recoverd }}{\text { Exergy supplied }}=\frac{\dot{W}_{\text {net }}}{\dot{W}_{\text {net }}+I_{\text {Tot }}}$,

in which $\dot{I}_{\mathrm{HRVG}}, \dot{I}_{\mathrm{p}}, \dot{I}_{\mathrm{st}}$ and $\dot{I}_{\text {Cond }}$ indicate the irreversibility rates in the heat regenerator of the pump, steam turbine, and condenser.

\section{Economic analysis}

For economic analysis, initially all direct and indirect costs of creation of solar ORC must be calculated. The main equipment purchasing costs are calculated according to the following formula using the relationships given in references [17] to [8]:

$$
\begin{aligned}
& C_{\mathrm{ST}}=2237\left(\dot{W}_{\mathrm{ST}}\right)^{0.41} \\
& C_{\mathrm{P}}=16800\left(\frac{\dot{W}_{\mathrm{P}}}{200}\right)^{0.67} \\
& C_{\mathrm{Cond}}=43\left(\dot{Q}_{\mathrm{Cond}}\right)^{0.68} \\
& C_{\mathrm{HRVG}}=11.6779 \times \dot{Q}_{\mathrm{HRVG}}+4416.105 \\
& C_{\mathrm{Gen}}=2447\left(\dot{W}_{\mathrm{Gen}}\right)^{0.49} \\
& C_{\mathrm{Equ}}=C_{\mathrm{ST}}+C_{\mathrm{HRVG}}+C_{\mathrm{P}}+C_{\mathrm{Gen}}+C_{\mathrm{Cond}} .
\end{aligned}
$$

In the above equations, $C_{\mathrm{st}}, C_{\mathrm{p}}, C_{\mathrm{Cond}}, C_{\mathrm{HRVG}}, C_{\mathrm{Gen}}$, and $C_{\mathrm{Equ}}$ are the purchase costs of steam turbine, pump, condenser, heat regenerator exchanger, power generator, and sum of all of these costs, respectively, given in USD. The amounts of $\dot{W}$ and $\dot{Q}$ are per $(\mathrm{kW})$.

The indirect costs including the miscellaneous costs $\left(C_{\text {miscella }}\right)$ are calculated by (38) equation in USD. In this equation, $\dot{W}_{\mathrm{Gen}}$ is the useful produced power of the system $(\mathrm{kW})$. The total investment costs $\left(C_{\mathrm{T}}\right)$ are the sum of equipment purchase and miscellaneous costs which is calculated by Eq. (39) [17]:

$C_{\text {miscella }}=183 \cdot \dot{W}_{\text {Gen }}$.
$C_{\mathrm{T}}=C_{\mathrm{Equ}}+C_{\text {mizella }}$.

The total cost $\left(C_{\mathrm{T}}\right)$ must be calculated annually $\left(\dot{C}_{\mathrm{ac}}\right)$ $\operatorname{per}\left(\frac{\text { USD }}{\text { year }}\right)[5]$ :

$\dot{C}_{\mathrm{ac}}=C_{\mathrm{T}} \cdot \mathrm{CRF}$

$\mathrm{CRF}=\frac{i(1+i)^{n}}{(1+i)^{n}-1}$.

In the above equation, CRF is the irreversibility factor in which $i$ is the efficiency coefficient and $\mathrm{n}$ is the years of useful equipment performance which are considered $10 \%$ and 20 years, respectively. The annual maintenance costs $\left(\dot{C}_{\mathrm{M \& O}}\right)$ is also a percentage of the annual costs $\left(\frac{\mathrm{USD}}{\text { year }}\right) . B$ is the percentage of maintenance costs which is usually taken as $4 \%$ :

$\dot{C}_{\mathrm{M \& O}}=\beta \cdot \dot{C}_{\mathrm{ac}}$.

The annual investment costs $\left(\dot{C}_{\text {anu }}\right)$ are the sum of equipment, maintenance, and annual fuel costs which is calculated by Eq. (44). The costs of the needed fuel for generation of inlet energy to the cycle which are calculated by Eq. (43). For doing this, first, the heat needed by the cycle $\left(\dot{Q}_{\mathrm{HRVG}}\right)$ per $(\mathrm{kW})$ should be calculated from the modelling equations. The amount of the needed fuel mass flow rate $\left(\dot{m}_{\mathrm{F}}\right)$ is entered considering the low thermal value of the chosen fuel LHV $\left(\frac{\mathrm{kJ}}{\mathrm{kg}}\right)$ and is calculated per $\left(\frac{\mathrm{kg}}{\mathrm{s}}\right) . \dot{c}_{\text {fuel }}$ is the cost of each kilogram of consumed fuel which is entered as the input to the modelling. By multiplying this cost to the consumed fuel discharge and again multiplying it to the sum of cycle work period during the year $(H)$ per second, cost of fuel $\left(C_{\mathrm{F}}\right)$ is calculated $\left(\frac{\mathrm{USD}}{\text { year }}\right)$ :

$\dot{m}_{\mathrm{F}}=\frac{\dot{Q}_{\mathrm{h}}}{\mathrm{LHV}}$

$\dot{C}_{\mathrm{F}}=\dot{m}_{\mathrm{F}} \times \dot{c}_{\text {fuel }} \times H$.

$C_{\text {anu }}=\dot{C}_{\text {ac }}+\dot{C}_{\mathrm{O \& M}}+\dot{C}_{\mathrm{F}}$.

One of the highly important parameters in economic analysis is the cost each kWh of energy $\left(\dot{C}_{\mathrm{kWh}}\right)$ which is calculated as follows [4]: in which $\mathrm{AE}\left(\frac{\mathrm{kWh}}{\mathrm{year}}\right)$ and $\dot{W}_{\text {net }}$ $(\mathrm{kW})$ and $H$ is the system working hours during the year $\left[\frac{\text { hour }}{\text { year }}\right]$.

$\mathrm{AE}=\dot{W}_{\text {net }} \times H$

$\dot{C}_{\mathrm{kWh}}\left[\frac{\mathrm{USD}}{\mathrm{kWh}}\right]=\frac{\dot{C}_{\mathrm{anu}}}{\mathrm{AE}}$. 


\section{Optimization method selection}

In reality, many parameters affect the performance of the ORC. Usually, these parameters simultaneously lead to increase or decrease in the performance parameters or costs. That is why the multi-objective optimization should be used to find the best point of design. Multi-objective optimization is a realistic model for many complex engineering optimization problems. In many real issues, the objective functions are in conflict with each other (minimizing cost and maximizing performance); therefore, optimizing a specific state with the single-objective method, compared to an objective function, can lead to unexpected results compared to the other objective functions. Unlike single-objective optimization, answer to these questions is not a single point. A reasonable solution for multi-objective problems is finding a series of answers that satisfies the objective functions in an acceptable level without being overcome by other answers. These solutions are known as the Pareto optimal set. All points of the Pareto chart are acceptable as the optimal solution for multi-objective optimization problems [5]; [13]. Selecting the appropriate objective function, the appropriate variables of optimization, and placement of proper conditions for designing play a key role in optimizing results. In this study, for designing the organic Rankine cycle, three optimization objective functions have been selected. First objective function is maximizing the thermal efficiency of the cycle which is calculated by Eq. (29). The second objective function is maximizing the amount of cycles exergy efficiency which is calculated by Eq. (31). The third objective function is minimizing the amount of the cost of producing each kilowatt of energy which is calculated from Eq. (46). Equations (47)-(49) show the objective optimization functions:

$\mathrm{OF}_{1}=\left(\eta_{\mathrm{I}}\right)$
$\mathrm{OF}_{2}=\left(\eta_{\mathrm{II}}\right)$
$\mathrm{OF}_{3}=\left(\dot{C}_{\mathrm{kWh}}\right)$.

Five design variables have been chosen for optimization. Turbine inlet temperature and pressure are two very important variable in designing organic cycles. In addition, the two variables as pinch temperature difference near the regenerator exchanger (Eqs. 4, 5) and condenser temperature difference (Eq. 20) are considered as the design variables. The upper and lower boundary limits of these variables are shown in Table 1. In order for the optimization to be reliable in terms of engineering and physics, a series of conditions must be entered in the optimization of the cycle design. The conditions are shown in Table 2. The design conditions must be considered in all the states of design and optimization.
Table 1 Optimization variables alongside with their changes range

\begin{tabular}{lll}
\hline Highest design level & Lowest design level & Design parameter \\
\hline $90 \%$ critical pressure & $10 \%$ critical pressure & $\left(P_{1}\right)$ \\
$180{ }^{\circ} \mathrm{C}$ & $70{ }^{\circ} \mathrm{C}$ & $\left(T_{1}\right)$ \\
$20{ }^{\circ} \mathrm{C}$ & $8{ }^{\circ} \mathrm{C}$ & $\left(\Delta T_{\mathrm{pp}}\right)$ \\
$12{ }^{\circ} \mathrm{C}$ & $5{ }^{\circ} \mathrm{C}$ & $\left(\Delta T_{\text {app }}\right)$ \\
$25{ }^{\circ} \mathrm{C}$ & $12{ }^{\circ} \mathrm{C}$ & $\left(\Delta T_{\text {Cond }}\right)$ \\
\hline
\end{tabular}

Table 2 Conditions of cycle designing and optimizing

$$
\begin{aligned}
& \text { Cons }_{1}=\left\{\begin{array}{c}
T_{\mathrm{H} 1}>T_{1} \\
T_{\mathrm{H} 2}>T_{8} \\
T_{\mathrm{H} 3}>T_{7 \mathrm{~b}} \\
T_{\mathrm{H} 4}>T_{6}
\end{array}\right\} \\
& \text { Cons }_{2}=X_{2}>0.99 \\
& \text { Cons }_{3}=T_{1} \geq T_{\mathrm{sat}}\left(P_{8}\right) \\
& \text { Cons }_{1}=\left\{\begin{array}{c}
T_{\mathrm{H} 1}>T_{1} \\
T_{\mathrm{H} 2}>T_{8} \\
T_{\mathrm{H} 3}>T_{7 \mathrm{~b}} \\
T_{\mathrm{H} 4}>T_{6}
\end{array}\right\} \\
& \text { Cons }_{2}=X_{2}>0.99 \\
& \text { Cons }_{3}=T_{1} \geq T_{\mathrm{sat}}\left(P_{8}\right)
\end{aligned}
$$

Various algorithms have been introduced to solve the problems of multi-objective optimization. In the current study, the three methods (1) NSGA-II (non-dominated sorting genetic algorithm version II);; (2) MOPSO (multiobjective particle swarm optimizers); and (3) MOEA/D (multi-objective evolutionary algorithm based on decomposition) have been used and compared

- NSGA-II method

The non-dominated sorting genetic algorithm is one of the best-known and most-applicable multi-objective optimization algorithms which was first introduced by Debb in 2002. This method is based on genetic algorithm. The main difference between NSGA-II and the simple genetic algorithm is in population layout. In this algorithm, the population is selected first based on quality and then based on distribution $[5,13]$.

- MOPSO method

Multi-objective particle swarm optimizers is a metaheuristic stemmed from PSO method of optimization. The difference between the two methods is in detection of the best position of the particle and particle local memory [6].

- MOEA/D method

This method is a modern multi-objective algorithm which solves a set of decompressed objectives in an interactional manner. The main difference between this 
method and the classical methods of multivariate optimization (weighted sum, goal programming, and goal attainment) is the reaction in finding the answers to different objectives [24]. In fact, this algorithm solves a multi-objective problem through several interactional single-objective problem. This algorithm was first introduced by Zhang and Li [24].

\section{Results and discussion}

To model the ORC, in this study, the exhaust of an engine cycle is used as an energy source input. The characteristics of this gas are shown in Table 3.

Modeling has been conducted for several fluids shown in Table 4. For fluid characteristics calculation, the Refprop.6 software developed by the National Institute of Standards and Technology of America has been used [9]. Other fixed parameters of modelling are shown in Table 5.

Initially, the effects of each of the design variables in Table 2 on three-mentioned objective function are investigated to determine what effects each variable alone will have on optimization objectives. For this purpose, at any stage, with assumption that four design variables are fixed, a variable is changed in a specific range and its effect on thermal efficiency, exergy efficiency of the cycle, and the production cost per each $\mathrm{kWh}$ of energy is studied and analyzed. Initially, the effect of turbine inlet pressure $\left(P_{1}\right)$, with assumption that other design variables is constant, and is being studied. In this study, turbine inlet temperature is $165^{\circ} \mathrm{C}$. Pinch and proximity temperature differences at regenerator exchanger are $10^{\circ} \mathrm{C}\left(\Delta T_{\mathrm{pp}}=10^{\circ} \mathrm{C}\right)$ and $8{ }^{\circ} \mathrm{C}$ $\left(\Delta T_{\text {app }}=8{ }^{\circ} \mathrm{C}\right)$, respectively. Condenser temperature difference is $12^{\circ} \mathrm{C}\left(\Delta T_{\text {Cond }}=12^{\circ} \mathrm{C}\right)$. Since the chosen fluids have different critical pressure, to examine all the different systems, the inlet turbine pressure is modelled as a percentage of the chosen fluid's critical pressure (between 0.3 and 0.9 of each fluid's critical pressure). The effect of turbine inlet pressure on exergy efficiency for various coolant fluids is provided in Fig. 2. In the hydrocarbon fluids, the increase in pressure leads to increase in exergy efficiency; however, in the fluids $R_{11}, R_{123}$, and $R_{141} B$

Table 3 Characteristics of gas input to the heat regenerator

\begin{tabular}{lll}
\hline Variable & Unit & Value \\
\hline Inlet gas temperature & ${ }^{\circ} \mathrm{C}$ & 200 \\
Inlet gas pressure & $\mathrm{MPa}$ & 0.12 \\
Inlet gas mass flow rate & $\mathrm{kg} / \mathrm{s}$ & 15 \\
Mass ratio of gas & & \\
$\mathrm{CO}_{2}$ & $\%$ & 51.2 \\
$\mathrm{~N}_{2}$ & $\%$ & 48.8 \\
\hline
\end{tabular}

which are all dry or isentropic fluids, the efficiency initially increases and then becomes fixed or decreases. The highest efficiency also belongs to these fluids. As for other fluids, the fluid $\mathrm{FA}_{245} \mathrm{R}$ has the highest exergy efficiency and the lowest efficiency belongs to $\mathrm{C}_{5} \mathrm{~F}_{12}$. Looking at the physical characteristics of the two fluids, it is observed that $\mathrm{FA}_{245} \mathrm{R}$ has a higher molecular weight and higher critical pressure that leads it to show a better exergy efficiency in a specific fluid temperature. The increase in turbine's pressure means an increase in enthalpy differences between the inlet and outlet of a turbine and thus increasing the work output of the turbine. In the fluids $\mathrm{R}_{11}, \mathrm{R}_{123}$, and $\mathrm{R}_{141} \mathrm{~B}$, the pump's input work increase slope is lower than turbine. However, by increasing the pressure over $0.5 P_{\mathrm{cr}}$, pump's input work increase slope is higher than turbine. This variation leads to output power to be initially increasing and then decreasing. In general, by increasing the inlet turbine pressure, pump's BWR increases.

Promotion of the turbine inlet pressure increases the cycle thermal efficiency. This procedure is shown in Fig. 3. Again, it is observed that the fluids $R_{11}, R_{123}$, and $R_{141} B$ have a higher thermal efficiency. Among the other fluids, $\mathrm{FA}_{245} \mathrm{R}$ and $\mathrm{C}_{12} \mathrm{~F}_{5}$ have the highest and lowest thermal efficiencies, respectively. It is clear that by the increase in work output of the turbine and pump input work, the cost will be increased; however, since the system useful power rises by the increase in pressure, the cost per $\mathrm{kWh}$ of energy generated undergoes the various trends by increasing turbine pressure. In the fluids $\mathrm{R}_{11}, \mathrm{R}_{123}$, and $\mathrm{R}_{141} \mathrm{~B}$, with the increase in the pressure, the costs per $\mathrm{kWh}$ of energy is initially decreased and then increased. It means that the slope of the rise in equipment cost is higher than that of the increase in the system power. For the rest of the fluids, the cost per each kWh of energy is first decreased significantly and afterwards, it is reduced by a mild slope or approximately fixed slope for some fluids. The trend of the changes in production costs per each $\mathrm{kWh}$ of energy is quite similar to the exergy efficiency trend (Fig. 4) which was quite predictable regarding what was mentioned.

In the following, the effect of the change in inlet turbine temperature $\left(T_{1}\right)$, with the assumption that other variables of designing are fixed, are being examined. In this study, the turbine inlet pressure temperature is taken as 0.5 of the critical pressure of each fluid $\left(P_{1}=0.5 P_{\mathrm{cr}}\right)$, Pinch temperature difference at regenerator exchanger is $10^{\circ} \mathrm{C}$ $\left(\Delta T_{\mathrm{pp}}=10^{\circ} \mathrm{C}\right)$, the proximity temperature difference at the regenerator exchanger is $8{ }^{\circ} \mathrm{C}\left(\Delta T_{\mathrm{app}}=8^{\circ} \mathrm{C}\right)$, and the condenser temperature difference is $12{ }^{\circ} \mathrm{C}$ $\left(\Delta T_{\text {Cond }}=12^{\circ} \mathrm{C}\right)$. Turbine inlet temperature variation is assumed in a range between 110 and $180^{\circ} \mathrm{C}$. The effects of turbine inlet temperature variation on exergy efficiency, thermal efficiency and energy production cost per kWh for different fluids are shown in Fig. 5. By increase in 
Table 4 Fluid characteristics [9]

\begin{tabular}{|c|c|c|c|c|}
\hline \multicolumn{3}{|c|}{ Physical specification } & \multirow[t]{2}{*}{ Chemical formula } & \multirow[t]{2}{*}{ Fluid } \\
\hline$P_{\mathrm{cr}}(\mathrm{MPa})$ & $T_{\mathrm{cr}}\left({ }^{\circ} \mathrm{C}\right)$ & $M(\mathrm{~kg} / \mathrm{kmol})$ & & \\
\hline 2.045 & 147.41 & 288.03 & $\mathrm{CF}_{3}\left(\mathrm{CF}_{2}\right) \mathrm{CF}_{3}$ & $\mathrm{C}_{5} \mathrm{~F}_{12}$ \\
\hline 3.8 & 152 & 58.12 & $\mathrm{CH}_{3}-\mathrm{CH}_{2}-\mathrm{CH}_{2}-\mathrm{CH}_{3}$ & Butane \\
\hline 3.64 & 134.7 & 58.12 & $\mathrm{CH}\left(\mathrm{CH}_{3}\right)_{2}-\mathrm{CH}_{3}$ & Isobutane \\
\hline 4.41 & 198 & 137.37 & $\mathrm{CC}_{13} \mathrm{~F}$ & $\mathrm{R}_{11}$ \\
\hline 3.6 & 183.68 & 152.93 & $\mathrm{CHC}_{12} \mathrm{CF}_{3}$ & $\mathrm{R}_{123}$ \\
\hline 4.25 & 204.2 & 16.95 & $\mathrm{CH}_{3} \mathrm{CC}_{12} \mathrm{~F}$ & $\mathrm{R}_{141} \mathrm{~B}$ \\
\hline 3.64 & 154.05 & 134.05 & $\mathrm{CF}_{3} \mathrm{CH}_{2} \mathrm{CHF}_{2}$ & $\mathrm{R}_{245} \mathrm{FA}$ \\
\hline
\end{tabular}

Table 5 Fixed coefficients of modeling

\begin{tabular}{lll}
\hline Value & Unit & Parameter \\
\hline 85 & $\%$ & Turbine efficiency \\
85 & $\%$ & Pump efficiency \\
20 & ${ }^{\circ} \mathrm{C}$ & Coolant fluid temperature \\
20 & $\mathrm{~kg} / \mathrm{s}$ & Coolant fluid mass flow rate \\
20 & ${ }^{\circ} \mathrm{C}$ & Medium temperature \\
1 & Atm & Medium pressure \\
10 & $\%$ & Annual interest rate \\
20 & Year & Year performance \\
8322 & Hours & Hours of operation during a year \\
4 & $\%$ & Operation and maintenance percent \\
\hline
\end{tabular}

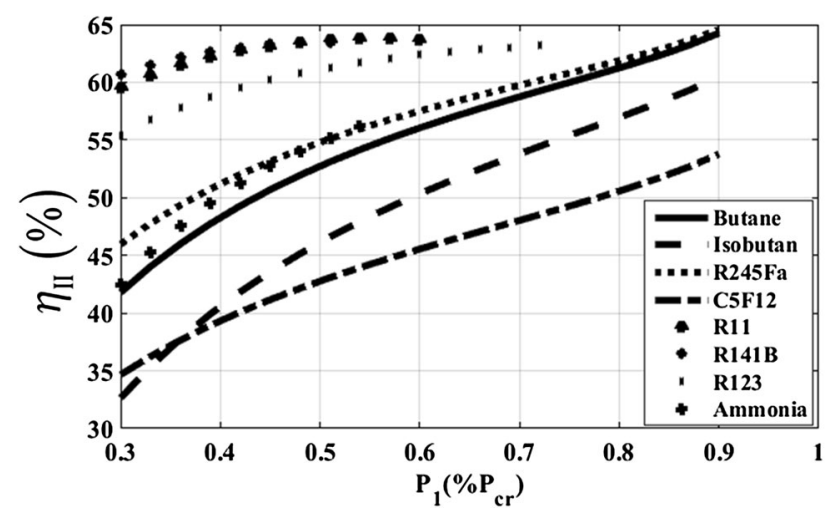

Fig. 2 Effect of changes in turbine inlet pressure on exergy efficiency

temperature, the fluid's discharge is reduced. This effect is visible in all studied fluids except ammonia. In ammonia, the fluid discharge increases by very little slope. As a result, amount of produced power is reduced by the increase in turbine inlet temperature, in all fluids except ammonia. On the other hand, due to the reduction in the fluid's discharge, amount of power needed for the pump is reduced; however, the net output power is reduced. With the reduction in fluid's discharge, the heat transfer rate on

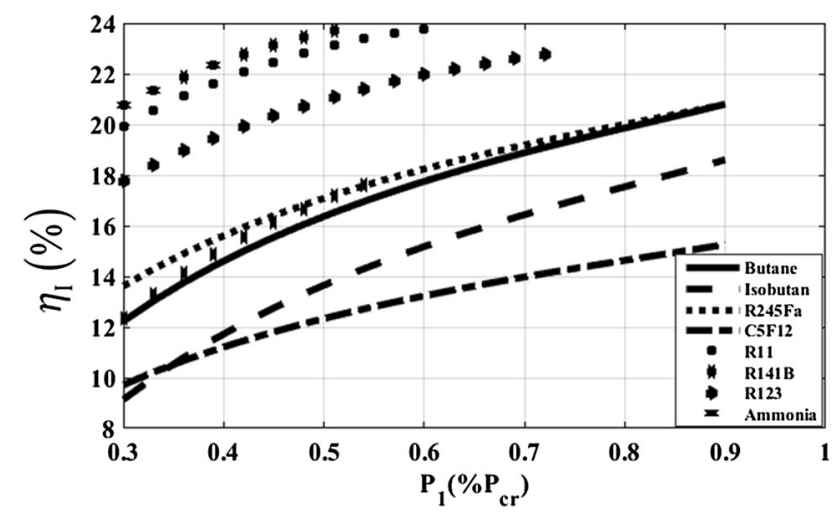

Fig. 3 Effect of turbine inlet pressure change on the thermal efficiency

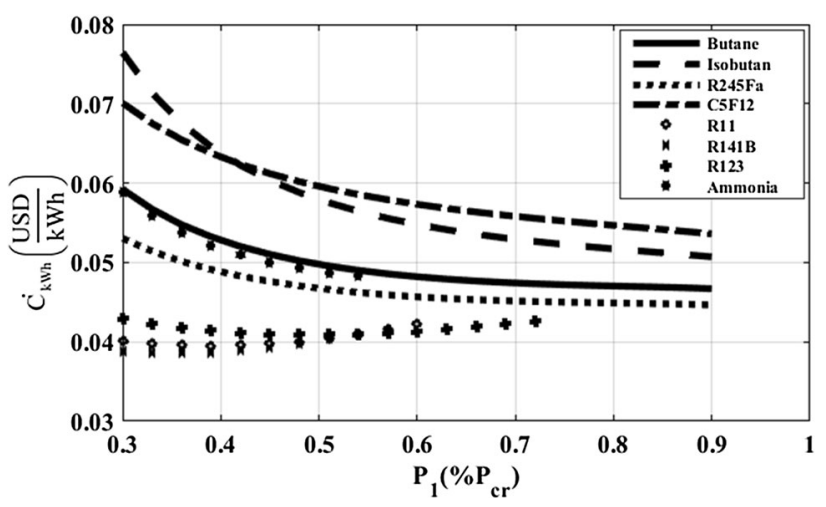

Fig. 4 Effect of change in turbine inlet pressure on the production cost per generation of each $\mathrm{kWh}$ of energy

the regenerator as well as heat transfer area, i.e., the regenerator's cost is reduced. Therefore, regarding the turbine and pump power reduction, the total costs are also reduced. With the increase in turbine inlet temperature, the irreversibility will be increased, and thus, exergy cycle efficiency will be reduced. As can be seen, only for ammonia, the fluid exergy efficiency increases by the increase in turbine inlet temperature. The reason behind this phenomenon is the very negative slope steam chart as well as the high steam pressure of this fluid that similar to water, by increasing the temperature in these low levels, 


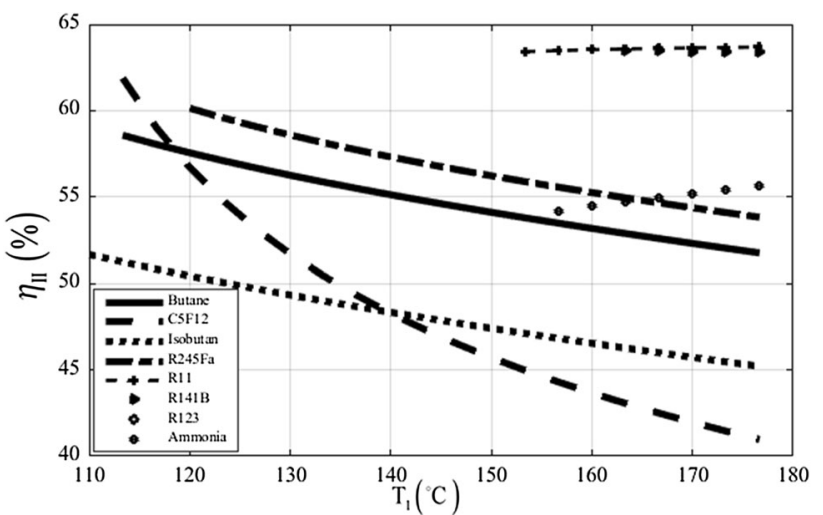

Fig. 5 Changes in exergy efficiency due to the turbine inlet temperature change

the exergy efficiency increases, since the amount of produced power is higher than the amount of irreversibility. As it can be seen in this figure, the fluid $\mathrm{C} 5 \mathrm{~F} 12$ has the highest reduction in exergy efficiency, while the fluids $R_{11}, R_{123}$, and $R_{141} B$ have the tiniest reduction slope. At low temperatures, the fluid $\mathrm{R}_{245} \mathrm{FA}$ has the lowest thermal efficiency; however, at higher temperatures, the $\mathrm{C}_{5} \mathrm{~F}_{12}$ has the lowest thermal efficiency. The reason behind this phenomenon is the high critical pressure of the fluid $\mathrm{R}_{245} \mathrm{FA}$ that leads to lesser fluid superheating at low temperature. However, at high temperatures, $\mathrm{C}_{5} \mathrm{~F}_{12}$ is over-superheated that indicates that superheating the wet fluids does not necessarily lead to a positive trend. The thermal efficiency is decreased, since the heat transfer rate at the regenerator is reduced and the cycle useful power is also reduced. Regarding the reduction slope, these two variables have different trends. In the fluids $\mathrm{R}_{11}, \mathrm{R}_{123}$, and $\mathrm{R}_{141} \mathrm{~B}$, the thermal efficiency will be a little increased. These fluids are all categorized under dry or isentropic fluids and increase in their thermal efficiency means that the increase in temperature reduces the amount of the heat transfer rate at regenerator more than the produced power which is reasonable and logical regarding the trend of steam slope. For other fluids, this trend is reverse, and for the fluid ammonia also due to the mentioned reasons, the trend is completely different and by the increase in the inlet turbine temperature, and the thermal efficiency is also increased. The costs of each $\mathrm{kWh}$ of energy are increased in the fluids whose thermal efficiency is decreased, and for the fluids with increased thermal efficiency, it is decreased which is reasonable regarding what was mentioned (Figs. 6, 7).

In the following, the effect of the change in Pinch temperature difference at heat exchanger regenerator $\Delta T_{\mathrm{pp}}$, with the assumption that other variables of designing are fixed, are being investigated. In this study, the turbine inlet pressure temperature is taken as 0.4 of the critical pressure of each fluid $\left(P_{1}=0.4 P_{\mathrm{cr}}\right)$, the inlet turbine temperature is

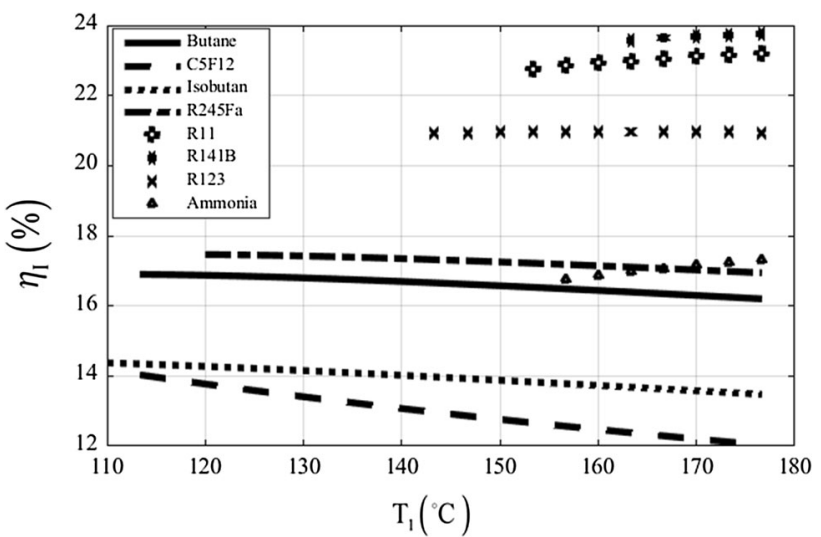

Fig. 6 Changes in thermal efficiency of the first law of thermodynamics due to the turbine inlet temperature change

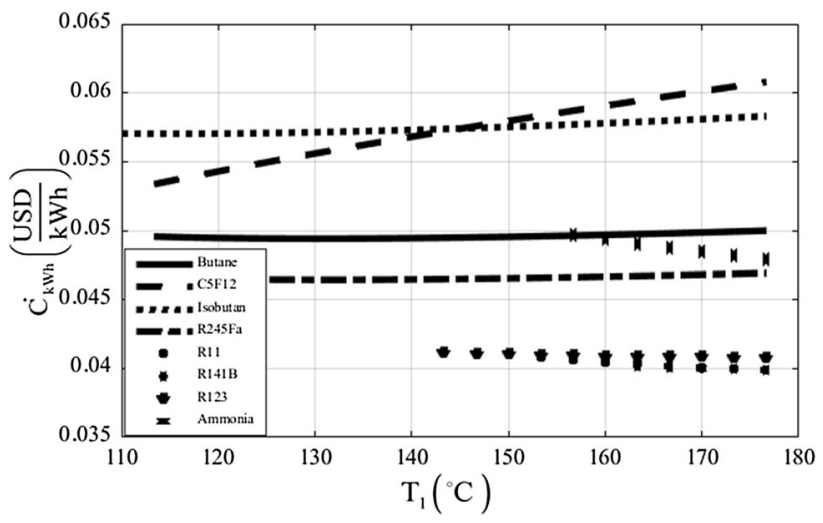

Fig. 7 Changes in the costs of each kWh of energy due to turbine inlet temperature change

$165{ }^{\circ} \mathrm{C}\left(T_{1}=165{ }^{\circ} \mathrm{C}\right)$, the proximity temperature difference at the regenerator exchanger is $8{ }^{\circ} \mathrm{C}\left(\Delta T_{\text {app }}=8{ }^{\circ} \mathrm{C}\right)$, and the condenser temperature difference is $12{ }^{\circ} \mathrm{C}$ $\left(\Delta T_{\text {Cond }}=12{ }^{\circ} \mathrm{C}\right)$. The increase in the pinch temperature difference leads to the decrease in the steam created by the regenerator that consequently leads to outlet turbine power as well as the useful power are decreased. By the decrease in the fluid's discharge, the amount of heat transfer rate at regenerator is decreased that leads to reduction of the costs. However, since the reduction slope of the useful power is bigger than that of the costs, the costs per each $\mathrm{kWh}$ of energy production is increased. Figure 8 shows the exergy efficiency variation due to temperature difference in regenerator exchanger pinch temperature. In this figure also, the highest efficiency belongs to the fluids $R_{11}$, $R_{123}$, and $R_{141} B$ and the lowest efficiency belongs to $C_{5} F_{12}$ and $\mathrm{R}_{245} \mathrm{FA}$. However, the thermal efficiency, since both useful power and heat transfer rate are decreased and the slope of their changes are approximately equal, undergoes little changes. Figure 9 shows the changes in thermal efficiency due to temperature difference in regenerator exchanger. In Fig. 10, it can be seen that the highest costs 


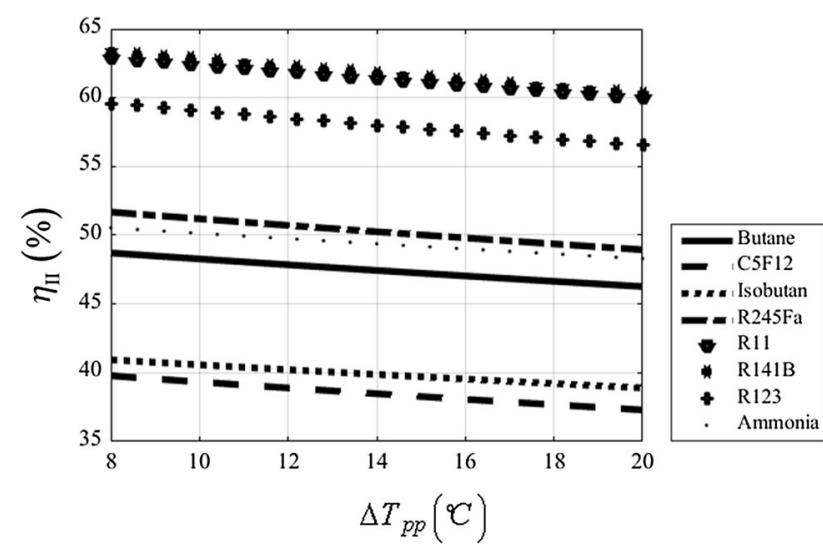

Fig. 8 Exergy efficiency changes due to difference in pinch temperature of regenerator exchanger

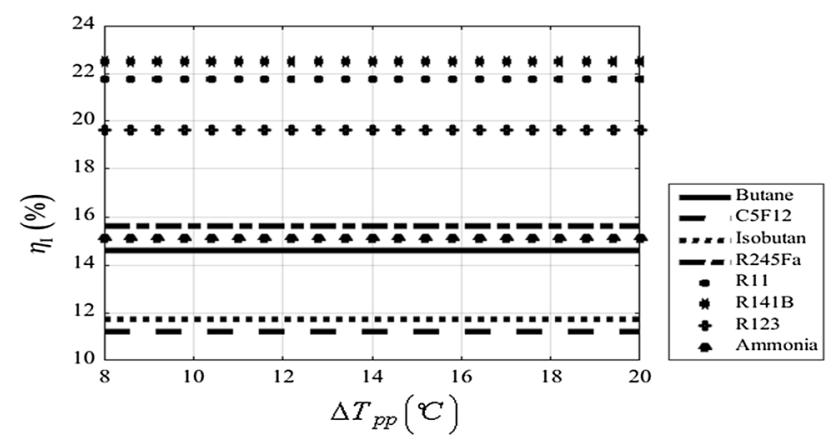

Fig. 9 Thermal efficiency changes due to difference in pinch temperature of regenerator exchanger

for each $\mathrm{kWh}$ of energy production belong to $\mathrm{C}_{5} \mathrm{~F}_{12}$ and $\mathrm{R}_{245} \mathrm{FA}$, while the lowest costs belong to $\mathrm{R}_{11}, \mathrm{R}_{123}$, and $R_{141} B$. With the increase in pinch temperature difference, the system irreversibility increases. That is why the designers tend to decrease this difference as much as possible.

In the following, the effect of the proximity temperature difference at the regenerator exchanger $\Delta T_{\text {app}}$, with the assumption that other variables of designing is fixed, and is being examined. In this study, the turbine inlet pressure temperature is taken as 0.4 of the critical pressure of each fluid $\left(P_{1}=0.4 P_{\text {cr }}\right)$, the inlet turbine temperature is $165^{\circ} \mathrm{C}$ $\left(T_{1}=165^{\circ} \mathrm{C}\right)$, the pinch temperature difference at the regenerator exchanger is $10^{\circ} \mathrm{C}\left(\Delta T_{\mathrm{pp}}=10^{\circ} \mathrm{C}\right)$, and the condenser temperature difference is $12{ }^{\circ} \mathrm{C}$ $\left(\Delta T_{\text {Cond }}=12^{\circ} \mathrm{C}\right)$. The results show that by the increase in proximity temperature difference, the amount of the steam produced by regenerator, and consequently, the turbine's work, is slightly increased which leads to the increase in the useful output power. This in turn would lead to a slight increase in cycle's thermal and exergy efficiencies for all the fluids. On the other hand, with the increase in output power, the costs will be increased; however, the slope of the increase in useful power will be bigger than that of the

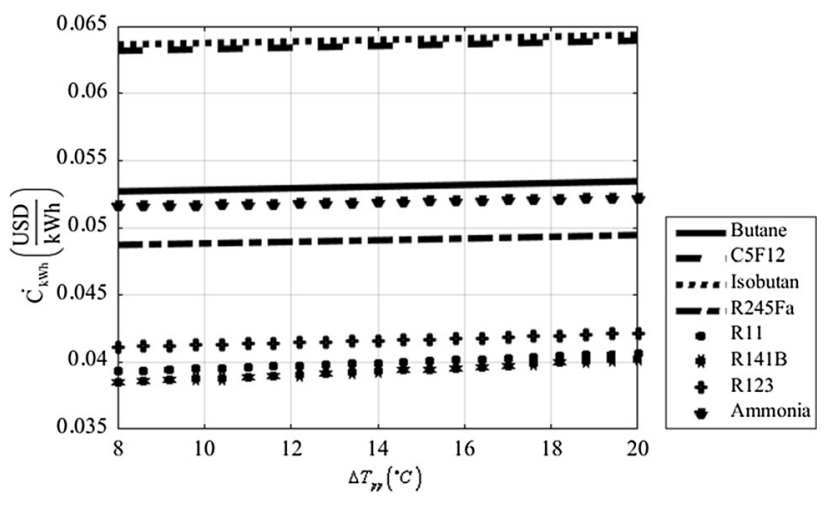

Fig. 10 Energy production costs changes due to difference in pinch temperature of regenerator exchanger

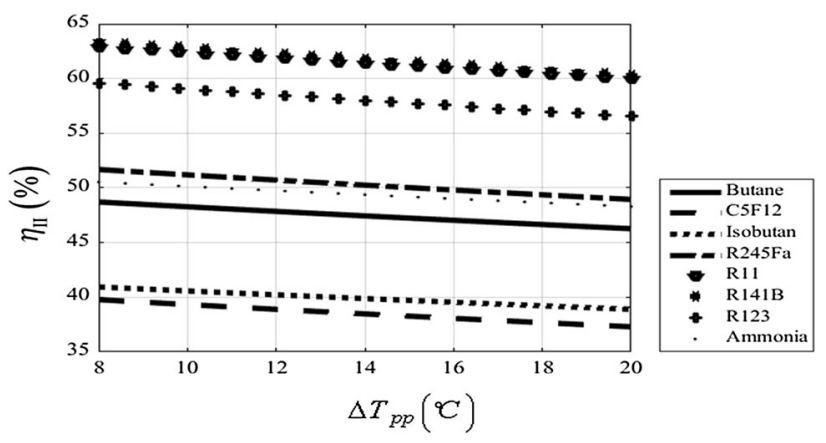

Fig. 11 Exergy efficiency changes due to changes in proximity temperature of the regenerator exchanger

costs which leads to reduction in production each $\mathrm{kWh}$ of power. In addition, the results indicate that the effects of the changes in proximity temperature difference on different parameters are inconsiderable. These variations are shown in Figs. 11, 12 and 13. In these figures, as was expected, again, the fluids $R_{11}, R_{123}$, and $R_{141} B$ had the highest exergy and thermal efficiencies and the lowest costs. The fluids $\mathrm{C}_{5} \mathrm{~F}_{12}$ and $\mathrm{FA}_{245} \mathrm{R}$ had the lowest efficiency and highest costs.

Finally, the effect of the condenser temperature difference $\Delta T_{\text {Cond }}$, with the assumption that other variables of designing are fixed, is being examined. In this study, the turbine inlet pressure temperature is taken as 0.4 of the critical pressure of each fluid $\left(P_{1}=0.4 P_{\mathrm{cr}}\right)$, the inlet turbine temperature is $165^{\circ} \mathrm{C}\left(T_{1}=165^{\circ} \mathrm{C}\right)$, the pinch temperature difference at the regenerator exchanger is $10{ }^{\circ} \mathrm{C}\left(\Delta T_{\mathrm{pp}}=10^{\circ} \mathrm{C}\right)$, and the proximity temperature difference is $12{ }^{\circ} \mathrm{C}\left(\Delta T_{\text {app }}=8{ }^{\circ} \mathrm{C}\right)$. With the increase in condenser temperature difference, the condenser's temperature is increased that leads to the increase in its pressure. This pressure increase means increase in the pressure behind the turbine that would lead to the decrease in turbine's work. This decrease in the work in total leads to the cycle useful work. This phenomenon leads to decrease in 


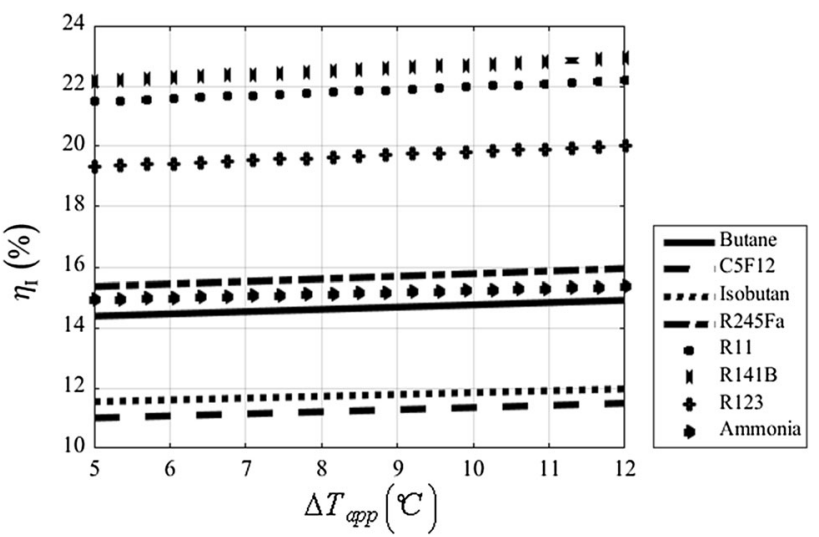

Fig. 12 Thermal efficiency changes due to changes in proximity temperature of the regenerator exchanger

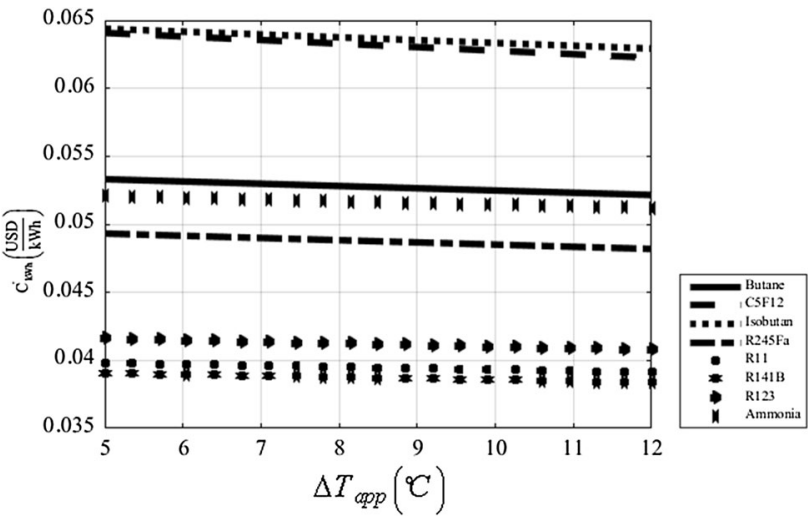

Fig. 13 Energy production costs changes due to changes in proximity temperature of the regenerator exchanger

exergy efficiency. With the increase in the condenser's temperature, the logarithmic temperature difference of the condenser is also increased that leads to reduction of heating area in the condenser and consequent reduction of costs. The decrease in turbine's power reduces its costs; however, the slope of the useful work of the system is bigger than that of the costs reduction that leads to the increase in production of each $\mathrm{kWh}$ if energy. With reduction of useful power, since the transferred heat in regenerator is not highly changed, the thermal efficiency is reduced. These changes are shown on Figs. 14, 15 and 16. Again, the fluids $R_{11}, R_{123}$, and $R_{141} B$ have the highest exergy and thermal efficiency and the lowest costs. The fluids $\mathrm{C}_{5} \mathrm{~F}_{12}$ and $\mathrm{FA}_{245} \mathrm{R}$ have the lowest efficiency and highest costs.

The three parameters exergy and thermal efficiencies, and the costs per production of each $\mathrm{kWh}$ of energy for three different states were shown for all the fluids. In all these three states, the inlet turbine temperature was $165{ }^{\circ} \mathrm{C}$ and the pinch and proximity temperature difference at the heat exchanger were considered 8 and $10{ }^{\circ} \mathrm{C}$, respectively.

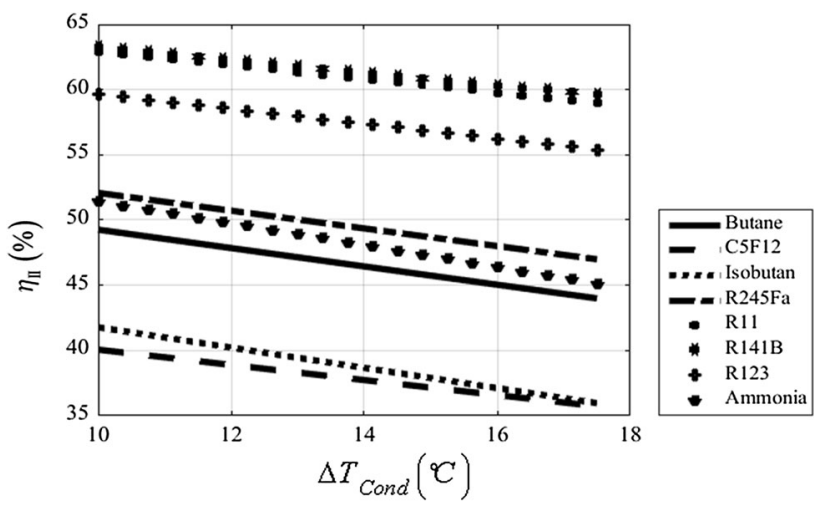

Fig. 14 Exergy efficiency changes due to changes in condenser temperature changes

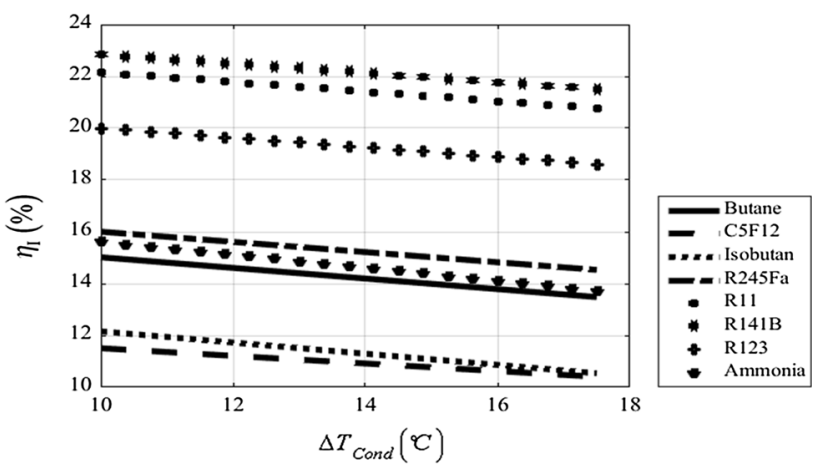

Fig. 15 Thermal efficiency changes due to changes in condenser temperature changes

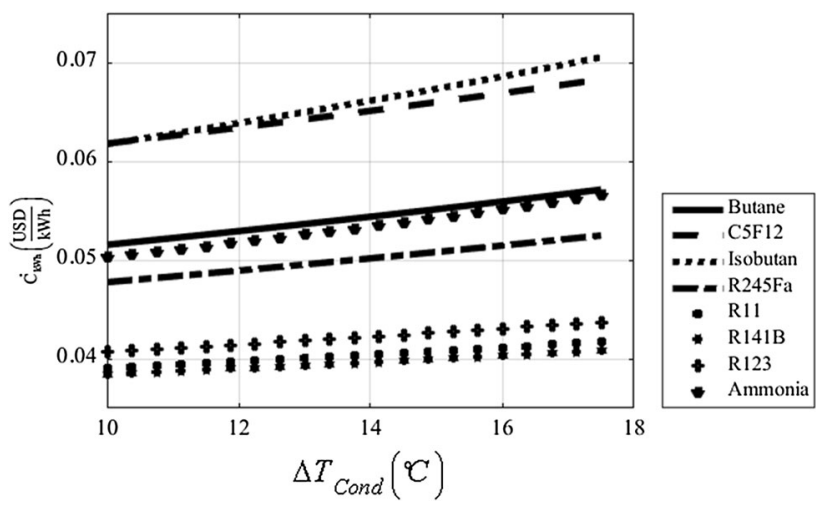

Fig. 16 Energy production costs changes due to changes in condenser temperature changes

In state 1, the inlet turbine pressure for all the coolers was taken as $1.5 \mathrm{MPa}$ and the condenser temperature difference was $7{ }^{\circ} \mathrm{C}$ in state 2 , the inlet pressure is the same $1.5 \mathrm{MPa}$, but the condenser temperature difference was $5{ }^{\circ} \mathrm{C}$ in state 3 , the inlet turbine pressure was taken as $2 \mathrm{MPa}$, and the condenser temperature difference was $7{ }^{\circ} \mathrm{C}$. As it is shown in the table, the reduction in condenser's temperature from state 4 to state 2 leads to the increase in efficiency and decrease in costs. This happens in a similar manner for all 
the fluids as for the ammonia, the thermal efficiency reaches to the maximum. The reason behind this phenomenon is the far more negative slope of steam of ammonia compared to other fluids. The condenser temperature decrease leads to the reduction of its pressure and the lower this pressure is, the better the fluid's performance will be. In the state changing from 1 to 3 , the condenser's pressure would remain unchanged; however, the inlet steam pressure will be increased. It is clear that this pressure increase will lead to the increase in thermal and exergy efficiencies and at the same time, the costs. In this state, also the ammonia is more clearly affected by pressure increase due to its temperature slope. Table 6 shows the first and second law efficiencies and the cost of power generation in the optimal states. The optimization characteristics for the three optimization algorithms are shown in Table 7.

For evaluation of the optimization results, the 3D Pareto chart (tri-objective) of the butane fluid is shown in Fig. 17 as an example. As it can be seen, the three methods show different Pareto charts. All of these illustrated points are the acceptable optimization results; however, as it was mentioned, using the Topsis selection method, one of the points is chosen as the optimal point in the three methods. Before the selection of the optimal point, the change range of the optimization objectives for all the fluids and the three optimization methods are provided in Tables 8, 9, and 10. This range is in fact the optimization objectives range in Pareto chart.

In Table 8, the highest and lowest exergy efficiency in the Pareto chart of the three optimization methods for all the fluids is provided. As it is seen, for the fluids $R_{11}, R_{123}$, and $R_{141} B$ which are dry or isentropic fluids, the obtained range in Pareto chart for their exergy is much lower than other fluids. It means that the optimization results for these three fluids in all the three methods show similar or close exergy efficiency, while for other fluids, it is not the same and the obtained range is significantly great. The results of the Pareto chart of the fluid $\mathrm{C}_{5} \mathrm{~F}_{12}$ contain the points with lowest exergy efficiency. In Table 9 that shows the highest and lowest thermal efficiency of Pareto chart for different fluids. Again, it is seen that the fluids $R_{11}, R_{123}$, and $R_{141} B$ have the lowest efficiency. This also indicates closeness of the thermal efficiency of these fluids according to the Pareto chart results. Again, $\mathrm{C}_{5} \mathrm{~F}_{12}$ has the lowest thermal efficiency. In Table 10, the lowest and highest obtained costs in the Pareto chart of the fluids optimization are shown. Again, the fluids $R_{11}, R_{123}$, and $R_{141} B$ cover a smaller range that indicates the closeness of the Pareto chart results for the three fluids.

Figure 18 shows the design optimal exergy efficiency for all the fluids in the three optimization methods. For all the fluids, the MOPSO method gives higher exergy efficiency. The highest obtained exergy efficiency in MOPSO method belongs to the fluid $\mathrm{R}_{11}$ which is $57.3 \%$ and the lowest exergy efficiency belongs the fluid butane which is $35 \%$ obtained in MOEA/D method. In addition, this chart shows that the difference in results of optimization for the three fluids $R_{11}, R_{123}$, and $R_{141} B$ is quite insignificant and for the rest of the fluids, especially the $\mathrm{C}_{5} \mathrm{~F}_{12}$, it is significant. This trend indicates that for the three fluids $R_{11}$, $\mathrm{R}_{123}$, and $\mathrm{R}_{141} \mathrm{~B}$, the three optimization methods show similar results. Among all the fluids, the highest efficiency improvement belongs to butane. For this fluid, the MOPSO method obtained an exergy efficiency of $47.7 \%$ higher than MOEA/D and 24.7\% higher than NSGA-II. However, the least improvement belonged to $\mathrm{R}_{11}$ in that the MOPSO method shows only $1.5 \%$ improvement in exergy efficiency compared to MOEA/D and $0.5 \%$ improvement in exergy efficiency compared to NSGA-II. In Fig. 19, the optimal amounts of efficiency of different fluids are shown. As it is seen, again, the MOPSO method has the highest thermal

Table 6 Fluid simulation results in three different states

\begin{tabular}{|c|c|c|c|c|c|c|c|c|c|}
\hline & \multicolumn{3}{|l|}{ State 1} & \multicolumn{3}{|l|}{ State 2} & \multicolumn{3}{|l|}{ State 3} \\
\hline & $\eta_{\mathrm{I}}(\%)$ & $\eta_{\mathrm{II}}(\%)$ & $C_{\mathrm{kWh}}\left(\frac{\mathrm{USD}}{\mathrm{kWh}}\right)$ & $\eta_{\mathrm{I}}(\%)$ & $\eta_{\mathrm{II}}(\%)$ & $C_{\mathrm{kWh}}\left(\frac{\mathrm{USD}}{\mathrm{kWh}}\right)$ & $\eta_{\mathrm{I}}(\%)$ & $\eta_{\mathrm{II}}(\%)$ & $C_{\mathrm{kWh}}\left(\frac{\mathrm{USD}}{\mathrm{kWh}}\right)$ \\
\hline Ammonia & 4.5 & 17.5 & 0.135 & 5.2 & 20.4 & 0.117 & 8 & 29.8 & 0.081 \\
\hline Butane & 15.5 & 51.6 & 0.050 & 15.9 & 53 & 0.048 & 17.7 & 57 & 0.047 \\
\hline $\mathrm{C}_{5} \mathrm{~F}_{12}$ & 14.8 & 51.6 & 0.053 & 15.1 & 52.8 & 0.052 & 16.4 & 61.7 & 0.050 \\
\hline Isobutane & 13 & 45.2 & 0.058 & 13.4 & 46.8 & 0.056 & 15.4 & 51.9 & 0.053 \\
\hline $\mathrm{R}_{11}$ & 21.7 & 63.8 & 0.038 & 22.1 & 64.9 & 0.037 & 23.4 & 65.7 & 0.038 \\
\hline $\mathrm{R}_{123}$ & 20.6 & 62.1 & 0.039 & 21 & 63.3 & 0.039 & 22.3 & 64.3 & 0.039 \\
\hline $\mathrm{R}_{141} \mathrm{~B}$ & 22.4 & 64.3 & 0.037 & 22.7 & 65.4 & 0.036 & 23.9 & 65.6 & 0.038 \\
\hline $\mathrm{R}_{245} \mathrm{FA}$ & 16.7 & 55.1 & 0.046 & 17.1 & 56.5 & 0.045 & 18.6 & 59.4 & 0.044 \\
\hline
\end{tabular}


Table 7 Different optimization algorithms settings

\begin{tabular}{llllll}
\hline NSGA-II & & MOPSO & & MOEA/D \\
\hline Maximum iteration & 500 & Maximum iteration & 500 & Maximum iteration & 500 \\
Population size & 50 & Number of particle & 50 & Population size & 50 \\
Crossover probability & 0.7 & Repository Size & 100 & Archive size & 100 \\
Mutation probability & 0.02 & Inertia Weight & 1 & Number of neighbors & 10 \\
Selection process & Tournament & Inertia weight damping rate & 0.95 & & \\
\hline
\end{tabular}

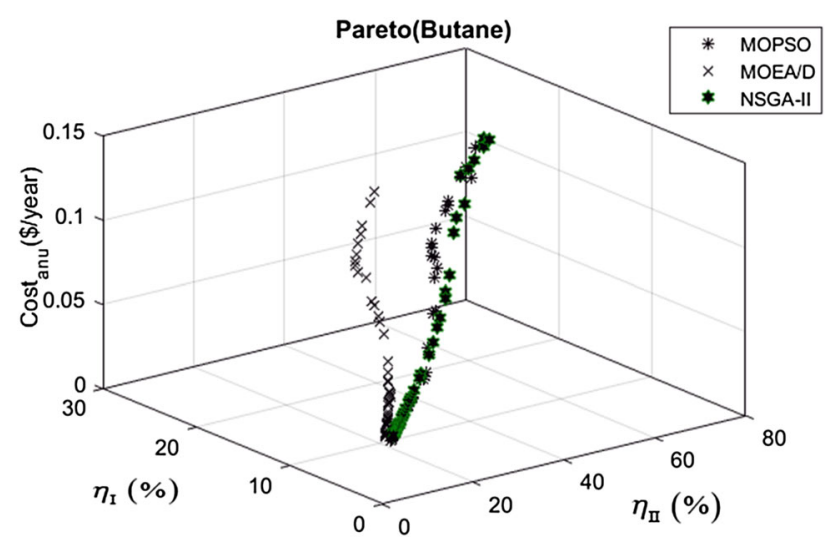

Fig. 17 3D Pareto chart of butane optimization efficiency for almost all the fluids. Only for the fluids $R_{11}$, $\mathrm{R}_{123}$, and $\mathrm{R}_{141} \mathrm{~B}$, the amounts obtained by NSGA-II are higher. In MOPSO method, the highest thermal efficiency belongs to the $\mathrm{R}_{11}$ with 24.1 and the lowest efficiency belongs to $\mathrm{C}_{5} \mathrm{~F}_{12}$ with $14.9 \%$. In MOEA/D, the fluid $\mathrm{R}_{11}$ with $25.7 \%$ and butane with $11.6 \%$ had the highest and lowest efficiency, respectively. However, in NSGA-II method, the $\mathrm{R}_{11}$ and butane had the highest and lowest thermal efficiency with 25.6 and $13.4 \%$, respectively. In butane, the MOPSO optimization method obtained a thermal efficiency by 68.3 and $46.4 \%$ higher than MOEA/D and NSGA-II, respectively. In $\mathrm{R}_{123}$, the MOPSO method shows a thermal efficiency of $3.0 \%$ lower and $2.6 \%$ higher as compared to NSGA-II and MOEA/D, respectively,
Table 8 Range of the changes in exergy efficiency in optimization of different fluids in three methods of optimization

\begin{tabular}{|c|c|c|c|c|c|c|}
\hline \multirow{2}{*}{$\begin{array}{l}\text { Fluid } \\
\eta_{\text {II }}\end{array}$} & \multicolumn{2}{|l|}{ MOEA/D } & \multicolumn{2}{|l|}{ MOPSO } & \multicolumn{2}{|l|}{ NSGA-II } \\
\hline & MIN (\%) & $\operatorname{MAX}(\%)$ & MIN (\%) & MAX (\%) & MIN (\%) & MAX (\%) \\
\hline Butane & 5.7 & 66.5 & 4.8 & 57.4 & 4.3 & 42.4 \\
\hline Isobutane & 5.0 & 63.7 & 4.7 & 57.7 & 8.6 & 54.1 \\
\hline $\mathrm{C}_{5} \mathrm{~F}_{12}$ & 4.9 & 55.9 & 3.6 & 51.6 & 3.6 & 49.8 \\
\hline $\mathrm{R}_{245} \mathrm{FA}$ & 9.6 & 67.0 & 6.3 & 59.1 & 6.9 & 66.3 \\
\hline $\mathrm{R}_{11}$ & 54.4 & 59.8 & 55.6 & 58.3 & 55.5 & 59.7 \\
\hline $\mathrm{R}_{123}$ & 49.6 & 59.5 & 49.7 & 57.1 & 52.4 & 59.3 \\
\hline $\mathrm{R}_{141} \mathrm{~B}$ & 53.2 & 57.9 & 55.4 & 57.9 & 51.1 & 59.3 \\
\hline Ammonia & 10.1 & 54.0 & 6.8 & 52.7 & 7.4 & 55.8 \\
\hline
\end{tabular}

Table 9 Range of the changes in thermal efficiency in optimization of different fluids in three methods of optimization

\begin{tabular}{|c|c|c|c|c|c|c|}
\hline \multicolumn{2}{|l|}{ NSGA-II } & \multicolumn{2}{|l|}{ MOPSO } & \multicolumn{2}{|l|}{ MOEA/D } & \multirow{2}{*}{$\begin{array}{l}\text { Fluids } \\
\eta_{\mathrm{I}}\end{array}$} \\
\hline MIN (\%) & MAX (\%) & MIN (\%) & $\operatorname{MAX}(\%)$ & MIN (\%) & MAX (\%) & \\
\hline 1.6 & 21.6 & 1.3 & 19.8 & 1.7 & 18.2 & Butane \\
\hline 1.3 & 19.5 & 1.3 & 17.8 & 2.3 & 19.2 & Isobutane \\
\hline 1.3 & 16.2 & 1.0 & 15.3 & 1.0 & 15.5 & $\mathrm{C}_{5} \mathrm{~F}_{12}$ \\
\hline 2.7 & 21.5 & 1.7 & 19.9 & 1.9 & 21.4 & $\mathrm{R}_{245} \mathrm{FA}$ \\
\hline 24.3 & 25.7 & 22.4 & 24.4 & 23.3 & 25.1 & $\mathrm{R}_{11}$ \\
\hline 22.0 & 24.8 & 20.9 & 23.4 & 21.2 & 24.8 & $\mathrm{R}_{123}$ \\
\hline 23.7 & 25.3 & 21.9 & 24.1 & 18.5 & 25.7 & $\mathrm{R}_{141} \mathrm{~B}$ \\
\hline 2.9 & 19.7 & 1.9 & 19.1 & 2.0 & 20.9 & Ammonia \\
\hline
\end{tabular}


Table 10 Range of the changes in costs in optimization of different fluids in three methods of optimization

\begin{tabular}{|c|c|c|c|c|c|c|}
\hline \multicolumn{2}{|c|}{ NSGA-II } & \multicolumn{2}{|c|}{ MOPSO } & \multicolumn{2}{|c|}{ MOEA/D } & \multirow{2}{*}{$\begin{array}{l}\text { Fluids } \\
C_{\mathrm{kWh}}\left(\frac{\mathrm{USD}}{\mathrm{kWh}}\right)\end{array}$} \\
\hline MIN & MAX & MIN & MAX & MIN & MAX & \\
\hline 0.03 & 0.012 & 0.03 & 0.1 & 0.03 & 0.11 & Butane \\
\hline 0.03 & 0.14 & 0.03 & 0.11 & 0.04 & 0.09 & Isobutane \\
\hline 0.03 & 0.09 & 0.03 & 0.09 & 0.03 & 0.08 & $\mathrm{C}_{5} \mathrm{~F}_{12}$ \\
\hline 0.03 & 0.11 & 0.03 & 0.09 & 0.03 & 0.11 & $\mathrm{R}_{245} \mathrm{FA}$ \\
\hline 0.01 & 0.05 & 0.03 & 0.05 & 0.01 & 0.05 & $\mathrm{R}_{11}$ \\
\hline 0.02 & 0.06 & 0.04 & 0.06 & 0.02 & 0.06 & $\mathrm{R}_{123}$ \\
\hline 0.02 & 0.04 & 0.03 & 0.05 & 0.01 & 0.05 & $\mathrm{R}_{141} \mathrm{~B}$ \\
\hline 0.04 & 0.08 & 0.03 & 0.08 & 0.03 & 0.08 & Ammonia \\
\hline
\end{tabular}

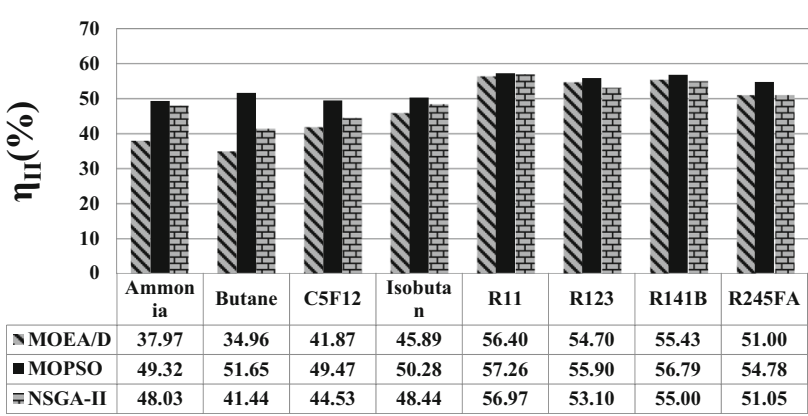

Fig. 18 Results of optimal thermal efficiency for the coolant fluids

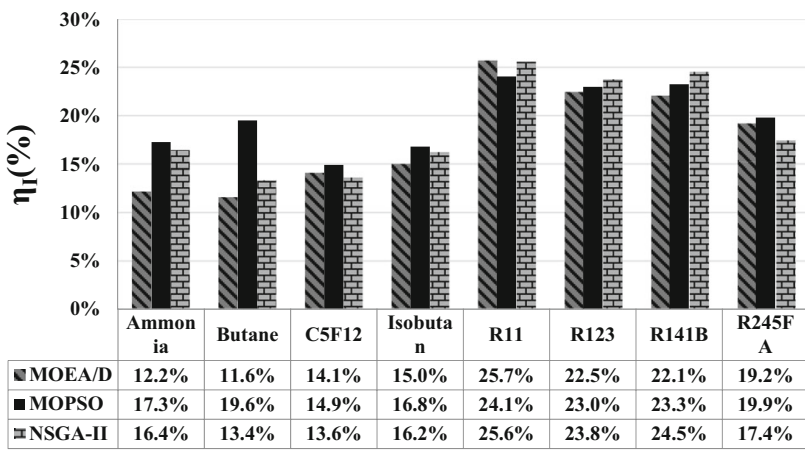

Fig. 19 Results of optimal exergy efficiency of different fluids

which has the lowest difference among all the fluids. In addition, the results indicated that in the fluids $R_{11}, R_{123}$, and $\mathrm{R}_{141} \mathrm{~B}$, the three methods of optimization have a little difference; however, for the rest of the fluids, the difference is significant. The reason behind this phenomenon is the temperature slope of these three fluids. As it was mentioned, these three fluids have a positive temperature slope while the other fluids have a negative temperature slope. These results indicate that the fluids with positive temperature slope show a better performance in terms of thermal efficiency.

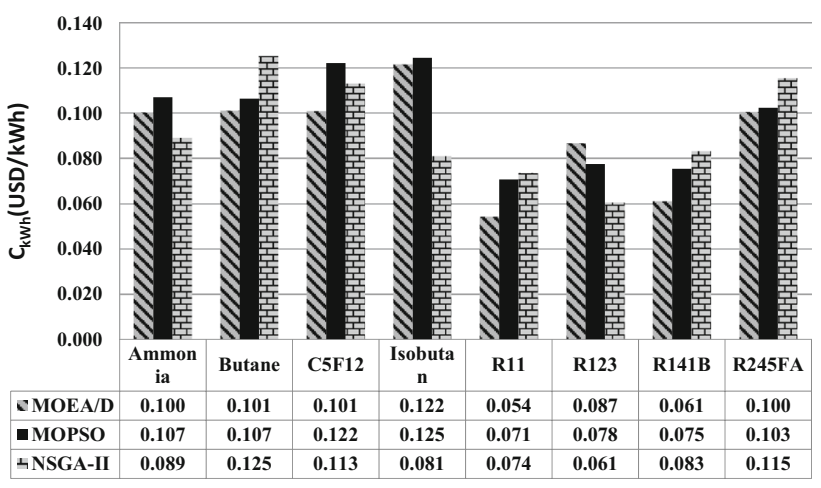

Fig. 20 Results of the optimal cost for the coolant fluids

In Fig. 20, the optimal amounts of costs are shown. The amounts of costs not only do depend the exergy and thermal efficiencies, but also depend on the useful power generation. That is why there is no clear trend for the optimal costs between the three methods of optimization for different fluids. However, generally the three fluids $\mathrm{R}_{11}$, $\mathrm{R}_{123}$, and $\mathrm{R}_{141} \mathrm{~B}$ have the lowest costs and the three fluids iso-butane, butane, and $\mathrm{C}_{5} \mathrm{~F}_{12}$ have the highest cost in the optimization method. In MOPSO method, the highest cost belongs to iso-butane which is 0.12 USD per $\mathrm{kWh}$ of energy production and the lowest costs belongs to $R_{11}$ with 0.07 USD per $\mathrm{kWh}$ of energy production. In the MOEA/D also the highest costs belongs to iso-butane with 0.12 USD per $\mathrm{kWh}$ of energy production and the lowest costs belongs to $\mathrm{R}_{11}$ with 0.05 USD per kWh of energy production. In the NSGA-II also the highest costs belongs to butane with 0.13 USD per kWh of energy production and the lowest costs belongs to $\mathrm{R}_{123}$ with 0.06 USD per $\mathrm{kWh}$ of energy production. As it is seen, the costs for butane, iso-butane, and $\mathrm{C}_{5} \mathrm{~F}_{12}$ are the highest and for $\mathrm{R}_{11}, \mathrm{R}_{123}$, and $\mathrm{R}_{141} \mathrm{~B}$ are the lowest. The results indicate that the fluids $R_{11}, R_{123}$, and $\mathrm{R}_{141} \mathrm{~B}$, due to their positive temperature slope, has a better performance and are more economic than other fluids with negative temperature slope.

In Fig. 21, the amounts of design optimal pressure are provided. The results of optimization show that the fluid Ammonia has higher optimal pressure and the fluid $\mathrm{C}_{5} \mathrm{~F}_{12}$ has the lowest design pressure. The reason behind this phenomenon is that the variable 'pressure' in the optimization is entered as a percentage of the fluid's critical pressure into the modelling. The higher the critical pressure, definitely the higher the inlet turbine pressure will be. As it is shown in Table 4, the Ammonia has the highest critical pressure and the $\mathrm{C}_{5} \mathrm{~F}_{12}$ has the lowest critical pressure that confirms the results in the chart of Fig. 21.

Figure 22 shows the optimal amounts of variable maximum temperature. As it is seen, since the inlet cycle gas temperature is assumed $200{ }^{\circ} \mathrm{C}$, the optimal temperature for all the fluids is almost in a high range and at the end of 


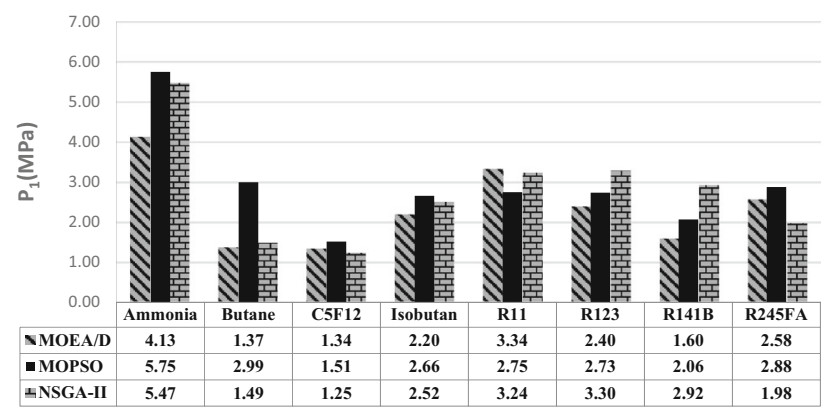

Fig. 21 Results of the optimal inlet turbine pressure for the studied coolant fluids

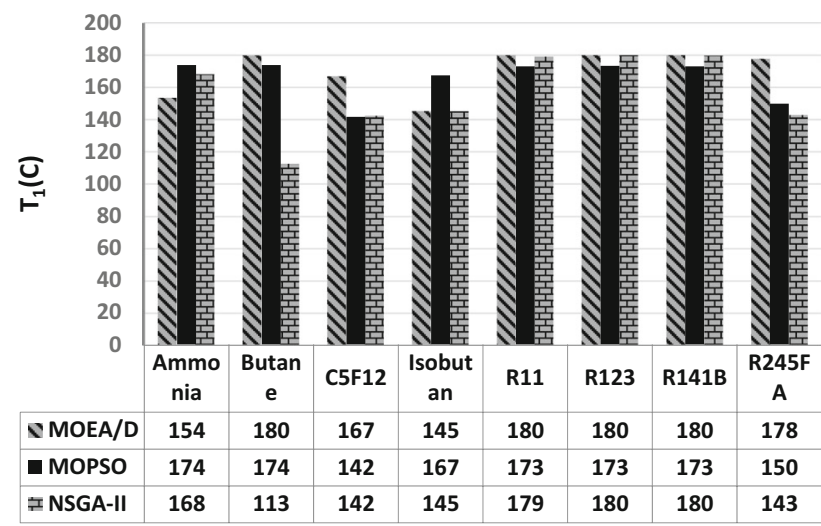

Fig. 22 Results of the optimal maximum temperature for the studied coolant fluids

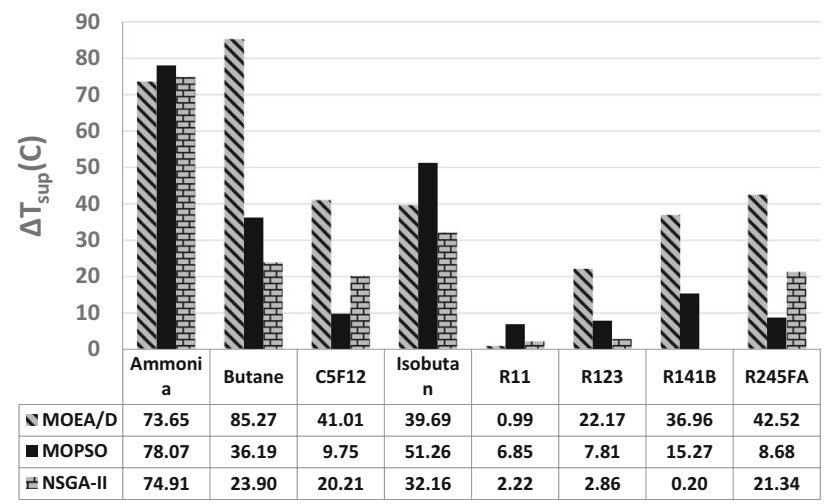

Fig. 23 Results of the degrees of optimal superheating for the studied coolant fluids

changes range. In the fluids $\mathrm{R}_{11}$ and $\mathrm{R}_{123}$, the optimal temperature is $180^{\circ} \mathrm{C}$. In the NSGA-II method, the butane had the lowest optimal maximum temperature with $112{ }^{\circ} \mathrm{C}$. In Fig. 23, the superheating degree of the inlet turbine fluid in the optimal state is shown. As it is seen, even though the fluids $R_{11}$ and $R_{123}$ are in their maximum temperature, they have the lowest degree of superheating due to the positive slope of the steam in their temperature-entropy chart that

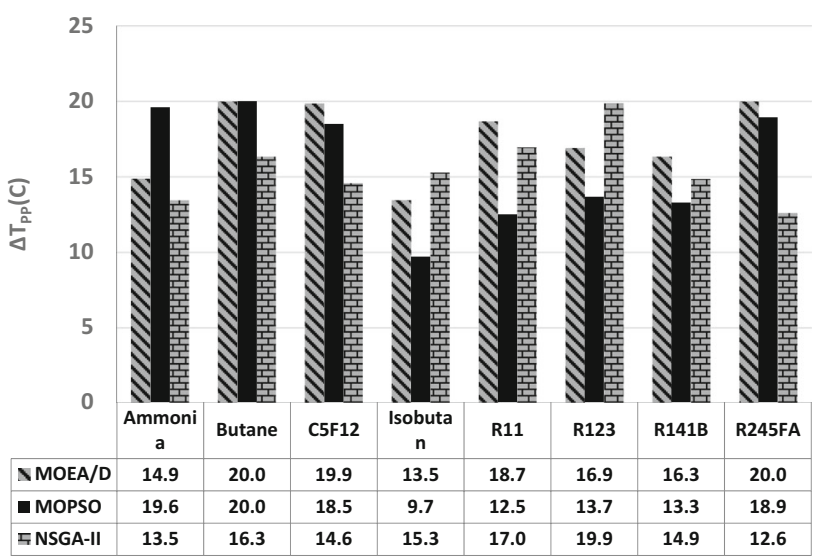

Fig. 24 Results of the optimal pinch temperature difference for the studied coolant fluids

minimizes the need for superheating. On the other hand, the fluids butane and ammonia are superheated to a great extent that is due to the negative slope of the steam in their temperature-entropy chart that maximizes the need for superheating.

Figures 24 and 25 show the optimal amounts of the pinch and proximity temperature difference at the regenerator. The most optimal temperatures are almost in the high levels of the changes range that indicate the higher effects of the increase in these temperature differences on the cost reduction compared to the decrease in thermodynamic performance of the system. As it is seen in the figures, the pinch and proximity temperature difference at the regenerator exchanger in the three fluids $R_{11}, R_{123}$, and $\mathrm{R}_{141} \mathrm{~B}$ is higher than the fluids iso-butane, butane, and $\mathrm{C}_{5} \mathrm{~F}_{12}$. This increase leads to efficiency decrease and at the same time, reduction in costs. The results of optimization indicate that cost reduction almost overcome the efficiency reduction and du to this, the temperature difference is paced in higher levels.

Figure 26 shows the optimal temperature difference in the condenser. As it was mentioned, this temperature difference means the increase in the condenser's temperature and consequently the increase in its pressure. The lower the condenser's pressure, the higher the ratio of the turbine's pressure will be. The chart of the optimal pressure ratio is also provided in Fig. 27. As it is seen, since the condenser temperature difference is the lowest for the fluid $R_{11}$, the highest ratio of turbine's pressure belongs to this fluid. For the ammonia and butane, this trend is reverse.

In Fig. 28, the amount of the useful produced power at the best state, is shown. As it is seen, the fluids iso-butane, and $\mathrm{C}_{5} \mathrm{~F}_{12}$ show higher useful power and the fluids $\mathrm{R}_{11}$, and $\mathrm{R}_{123}$ showed the lowest useful power. In Fig. 29, the ratio of pump to turbine power for the design optimal state has been shown. As it is seen, the fluid $R_{141} B$ has the lowest 


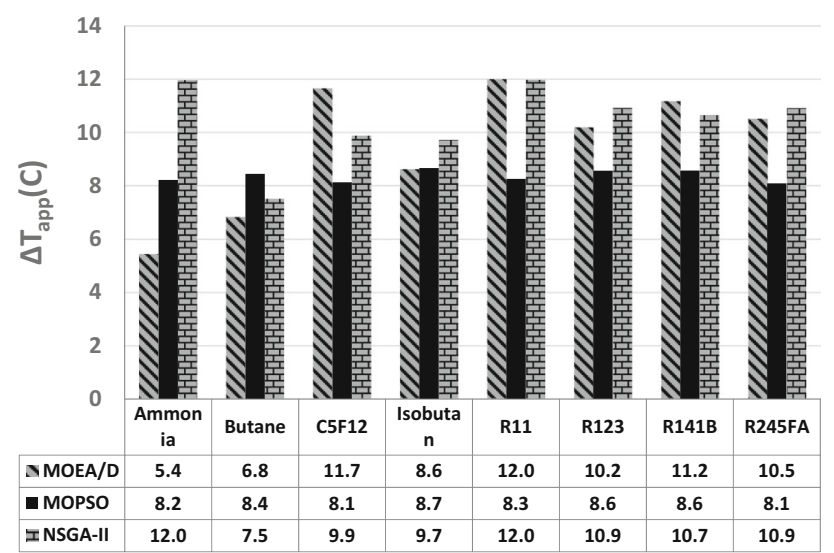

Fig. 25 Results of the optimal proximity temperature difference for the studied coolant fluids

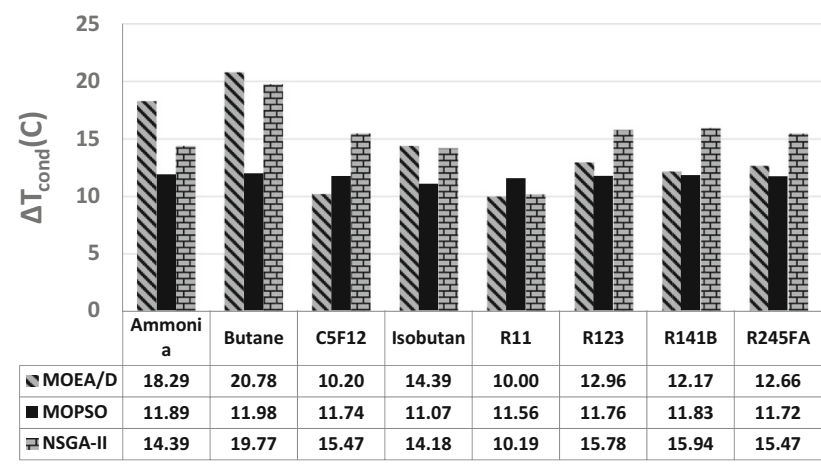

Fig. 26 Results of the optimal condenser temperature difference for the studied coolant fluids

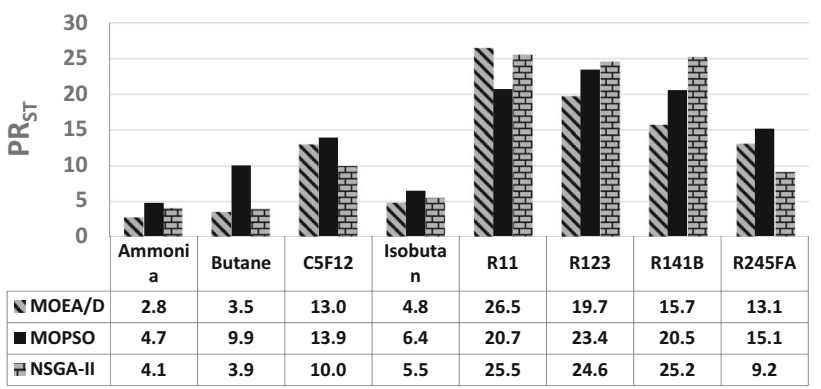

Fig. 27 Results of the optimal turbine pressure ratio for the studied coolant fluids

ratio; however, in general, this ratio is almost the same for all the fluids in all three optimization methods.

\section{Conclusion}

In the current study, first, after reviewing the modelling and using the organic Rankine cycle at low temperature, conservation equations of mass and energy for the cycle equipment were provided. Then, the model of the

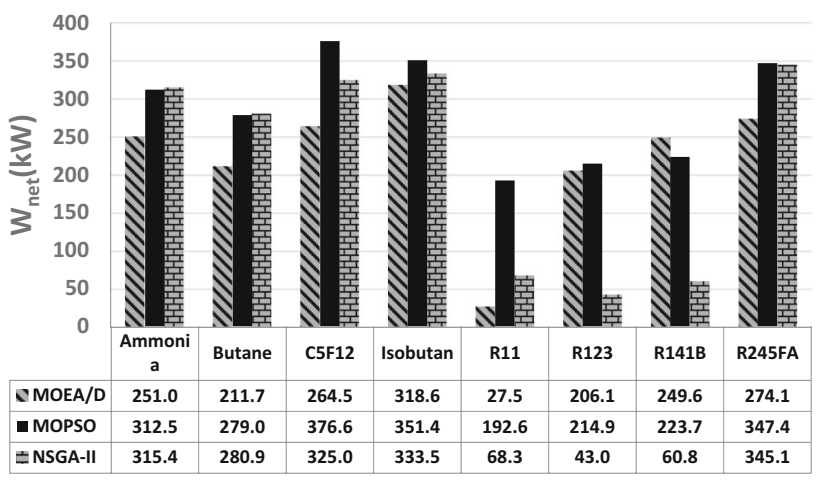

Fig. 28 Results of the optimal useful produced power in all the fluids

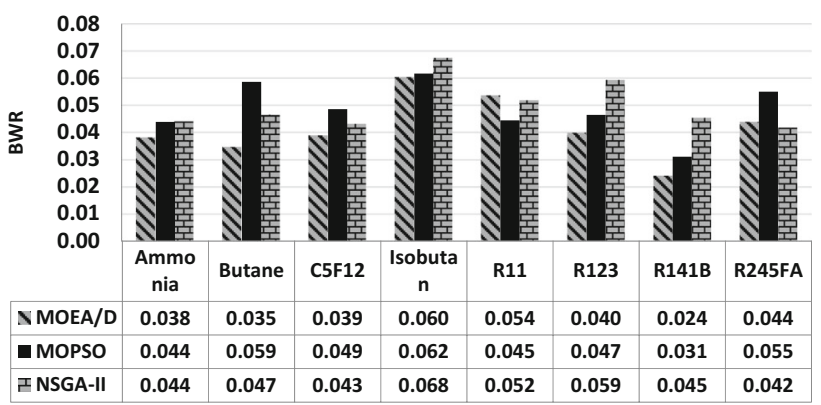

Fig. 29 Results of the optimal ratio of pump to turbine power in all fluids

economic modelling of the equipment was elaborated and afterwards, the parametric evaluation of this cycle for the variables inlet turbine temperature and pressure, the pinch and proximity temperature difference at the regenerator exchanger, and the condenser's temperature difference were analyzed. Finally, the tri-objective optimization results (exergy efficiency, thermal efficiency, and cost of each $\mathrm{kWh}$ ) in the three methods NSGA-II, MOPSO, and MOEA/D were provided and analyzed.

The results can be summarized as follows:

1. The inlet turbine temperature and pressure have the greatest effect on the thermal and exergy efficiency as well as the costs. However, the effects of the other three parameters (pinch and proximity temperature difference at the regenerator exchanger and condenser temperature difference) is lower than those two. These five variables have different effects on the efficiency and costs. The increase in the system performance will lead to the increase in costs.

2. Choosing the working fluid is very important and vital for the ORC. The dry fluids $R_{11}, R_{123}$, and $R_{141} B$ has the best performance in terms of exergy and thermal efficiency as well as the costs. The fluid $\mathrm{R}_{11}$ with the exergy efficiency of $57.3 \%$ and thermal efficiency of $25.7 \%$ and cost of 0.0542 USD per kWh of energy production had the best performance among all the 
fluids. It indicates that using the dry fluids instead of wet fluids in the organic cycles has a better performance in terms of efficiency and costs. However, in terms of useful power production, these fluids act quite contrariwise. In power generation, the fluid generates the highest power with $376.6 \mathrm{kWh}$ and the fluid $\mathrm{R}_{11}$ generates the lowest power with $27.5 \mathrm{kWh}$. This phenomenon indicates the importance of the desired objective in cycle design. In cases there is no limits in terms of need to power, the fluid $\mathrm{R}_{11}$ is the best choice; however, when a specific power is desired, it is not the best choice.

3. The selection of the optimization method depends on the desired objective of optimizing and the selected fluid. For optimization, the MOPSO method shows the best performance in terms of exergy and thermal efficiency; however, in terms of the costs, the three methods show different performance in different fluids. In butane, The MOPSO method with a 47.75 exergy efficiency improvement compared to MOEA/D, and 68.3 thermal efficiency improvement compared to MOEA/D, shows the best performance; however, there are different trends in reduction of the costs in the fluid and we cannot definitely choose a method.

Open Access This article is distributed under the terms of the Creative Commons Attribution 4.0 International License (http://crea tivecommons.org/licenses/by/4.0/), which permits unrestricted use, distribution, and reproduction in any medium, provided you give appropriate credit to the original author(s) and the source, provide a link to the Creative Commons license, and indicate if changes were made.

\section{References}

1. Ahmadi, P., Rosen, M.: Exergo-environmental analysis of an integrated organic Rankine cycle for trigeneration. Energy Convers. Manag. 64, 447-453 (2012)

2. Ashouri, M., Razi Astaraei, F., Ahmadi, M.: Thermodynamic and economic evaluation of a small-scale organic Rankine cycle integrated with a concentrating solar collector. Int. J. Low Carbon Technol. 1, 1-12 (2015)

3. Ataei, A., Safari, F., Choi, J.K.: Thermodynamic performance analysis of different organic Rankine cycles to generate power from renewable energy resources. Am. J. Renew. Sustain. Energy 2, 31-38 (2015)

4. Ayachi, F., Boulawz, Ksayer E., Zoughaib, A., Neveu, P.: ORC optimization for medium grade heat recovery. Energy 68, 47-56 (2014)

5. Bejan, A., Tsatsaronis, G.: Thermal design and optimization. Wiley, New York (1996)

6 Coello, C.C., Lechuga, M.S.: MOPSO: a proposal for multiple objective particle swarm optimization. Evolut. Comput. 2, 1051-1056 (2002)
7 Darvish, K., Ehyaei, M., Atabi, F., Rosen, M.: Selection of optimum working fluid for organic rankine cycles by exergy and exergy-economic analyses. Sustainability 7, 15362-15383 (2015)

8 Lecompte, S., Huisseune, H., van den Broek, M., De Schampheleire, S., De Paepe, M.: Part load based thermo-economic optimization of the organic Rankine cycle (ORC) applied to a combined heat and power (CHP) system. Appl. Energy 111, 871-881 (2013)

9 Lemmon EW, Huber ML, McLinden MO (2002) NIST reference fluid thermodynamic and transport properties-REFPROP, 3rd: version

10 Liu, B.T., Chien, K.H., Wang, C.C.: Effect of working fluids on organic Rankine cycle for waste heat recovery. Energy 29, 1207-1217 (2004)

11 Pierobon, L., Nguyen, T.V., Larsen, U., Haglind, F., Elmegaard, B.: Multi-objective optimization of organic Rankine cycles for waste heat recovery: application in an offshore platform. Energy 58, 538-549 (2013)

12 Quoilin, S., Broek, M.V.D., Declaye, S., Dewallef, P., Lemort, V.: Techno-economic survey of organic Rankine cycle (ORC) systems. Renew. Sustain. Energy Rev. 22, 168-186 (2013)

13 Rao, S.S., Rao, S.: Engineering optimization: theory and practice. Wiley, New York (2009)

14 Rayegan, R., Tao, Y.X.: A procedure to select working fluids for solar organic Rankine cycles (ORCs). Renew. Energy 36, 659-670 (2011)

15 Roy, J.P., Mishra, M.K., Misra, A.: Parametric optimization and performance analysis of a waste heat recovery system using organic Rankine cycle. Energy 35, 5049-5062 (2010)

16 Saleh, B., Koglbauer, G., Wendland, M., Fischer, J.: Working fluids for low-temperature organic Rankine cycles. Energy 32, 1210-1221 (2007)

17 Scardigno, D., Fanelli, E., Viggiano, A., Braccio, G., Magi, V.: A genetic optimization of a hybrid organic Rankine plant for solar and low-grade energy sources. Energy 91, 807-815 (2015)

18 Tchanche, B.F., Papadakis, G., Lambrinos, G., Frangoudakis, A.: Fluid selection for a low temperature solar organic Rankine cycle. Appl. Therm. Eng. 29, 2468-2476 (2009)

19 Tchanche, B.F., Lambrinos, G., Frangoudakis, A., Papadakis, G.: Low-grade heat conversion into power using organic Rankine cycles-a review of various applications. Renew. Sustain. Energy Rev. 15, 3963-3979 (2011)

20 Wang, Z.Q., Zhou, N.J., Guo, J., Wang, X.Y.: Fluid selection and parametric optimization of organic Rankine cycle using low temperature waste heat. Energy 40, 107-115 (2012)

21 Wang, J., Yan, Z., Wang, M., Li, M., Dai, Y.: Multi-objective optimization of an organic Rankine cycle (ORC) for low grade waste heat recovery using evolutionary algorithm. Energy Convers. Manag. 71, 146-158 (2013)

22 Wei, D., Lu, X., Lu, Z., Gu, J.: Performance analysis and optimization of organic Rankine cycle (ORC) for waste heat recovery. Energy Convers. Manag. 48, 1113-1119 (2007)

23 Yamamato, T., Furuhata, T., Arai, N., Mori, K.: Design and testing of the organic Rankine cycle. Energy 26, 239-251 (2001)

24 Zhang, Q., Li, H.: MOEA/D: a multiobjective evolutionary algorithm based on decomposition. IEEE Trans. Evol. Comput. 11, 712-731 (2007)

\section{Publisher's Note}

Springer Nature remains neutral with regard to jurisdictional claims in published maps and institutional affiliations. 